\title{
Aguas subterráneas, humedales y servicios ecosistémicos en Colombia
}

\author{
Groundwater, wetlands and ecosystem services in Colombia
}

Teresita Betancur-Vargas, Daniel A. García-Giraldo, Angélica J. Vélez-Duque, Angélica M. Gómez, Carlos Flórez-Ayala, Jorge Patiño y Juan Á. Ortíz-Tamayo

\section{Resumen}

A raíz de los efectos del ENSO (2010 - 2011), en Colombia se emprendió, entre otras iniciativas, el proyecto de generación de insumos técnicos para la delimitación de ecosistemas estratégicos de páramos y humedales. Algunos de estos ecosistemas están relacionados con las aguas subterráneas al intercambiar aportes en zonas de recarga, tránsito o descarga de acuíferos. En épocas lluviosas los humedales contribuyen a la regulación de caudales y en tiempo de sequía se mantienen gracias al agua que les llega desde el subsuelo. Algunas acciones humanas sobre el terreno o los acuíferos ponen en riesgo sus funciones y servicios y la de los ecosistemas relacionados. En el marco del convenio No. 15-13-014-068 CE entre el Instituto de Investigación de Recursos Biológicos Alexander von Humboldt y la Universidad de Antioquia, quedó manifiesta la interconexión entre humedales y aguas subterráneas en Colombia. A partir de la información disponible se identificaron catorce humedales relacionados con sistemas hidrogeológicos, para una primera caracterización de los servicios ecosistémicos con base en ejercicios de superposición cartográfica y en el estado y tendencia de los principales factores de cambio. Se identifica en este estudio el estado y tendencia tanto de los servicios ecosistémicos como de los factores de cambio resaltando los aspectos más importantes encontrados en los catorce humedales analizados. Es importante resaltar que se deben aunar esfuerzos para integrar y hacer coherente la formulación y aplicación de medidas de manejo y protección desde los Planes Ambientales referidos al agua y su biodiversidad, incluyendo tanto humedales como acuíferos.

Palabras clave. Adaptación. Gestión del riesgo. Interacción acuífero humedal. Tránsito y descarga. Zonas de recarga.

\begin{abstract}
Because of the effects of ENSO (2010 - 2011), a new project was undertaken in Colombia, among other initiatives, to generate technical inputs for the delimitation of strategic ecosystems of mountaintop moors and wetlands. Some of these ecosystems are related to groundwater when they exchange flows in recharge, transit and discharge zones of the aquifers. In wet periods the wetlands contribute to the regulation of river flow and in dry periods they maintain flow due to the contributions from aquifers. Some human actions on land or on the aquifers can put their functions and services to their related ecosystems at risk. The interconnection between wetlands and groundwater in Colombia was revealed as a result of the mutual collaboration agreement No. 15-13-014-068 CE between the Institute Alexander von Humboldt and the University of Antioquia. From the information available, fourteen wetlands' interactions with groundwater were identified, to make a first
\end{abstract}


characterization of their ecosystem services based on cartographic overlay exercises and to determine their current status and major factors of change. In this study the current state and trends of both the ecosystem services as well as the factors of change factors, and the most relevant aspects found in the fourteen wetlands analyzed are highlighted. It is important to emphasize that efforts must be made to integrate and make coherent the formulation and application of management and protection measures for Environmental Plans related to water and its biodiversity, including both wetlands and aquifers.

Key words. Aquifer-wetland interaction. Recharge. Transit and discharge zones. Risk management. Adaptation.

\section{Introducción}

Las inundaciones que se vivieron a raíz del fenómeno climático La Niña entre 2010 y 2011, por eventos de precipitación de alta intensidad, motivaron la intervención del Estado hacia la generación de conocimiento en torno a la localización, funcionalidad y dinámica de los humedales del país. La adaptación es la ruta para la permanencia y la supervivencia. Los efectos e impactos de la variabilidad pueden poner en riesgo los servicios que proporcionan los ecosistemas para el bienestar humano y el sostenimiento de las especies. En 2015 ha sido El Niño el fenómeno que ha generado sequía en amplias zonas del país y problemas por desabastecimiento de agua. La ocurrencia de ambos fenómenos impone retos para encarar su comprensión y el conocimiento del territorio, de manera que ante futuros eventos de la misma naturaleza se pueda estar preparado para responder oportuna y adecuadamente, mediante acciones preventivas que minimicen los impactos negativos.

La condición ecológica de los humedales como cunas de biodiversidad está estrechamente relacionada con sus características hidrológicas, al ser estas las que determinan el hidroperíodo -definido como el patrón estacional del nivel del agua del humedal-, hecho que está relacionado con el incremento o caída de los niveles de agua superficial o subterránea e influenciado por las entradas y salidas de agua. Tras identificar la precipitación, la escorrentía y el flujo base como las fuentes que pueden aportar agua al humedal, se va evidenciando la importancia y la frecuencia de la relación entre los ambientes superficial y subterráneo en torno a los ecosistemas que los habitan.

En el contexto planetario, los humedales han sido reconocidos como sistemas dotados de un valor hidrológico, cultural y paisajístico que los convierte en foco de atención. En torno a estos se han firmado tratados y convenios y se han formulado directrices para su conservación y preservación. La convención Ramsar (Ramsar 1971) y el programa de Evaluación de Ecosistemas del Milenio (EEM 2005) han representado, entre otras, iniciativas con trascendencia internacional, en las que estos ecosistemas estratégicos han sido foco de atención.

En el marco de servicios ecosistémicos, cuando se hace referencia a los humedales, las funciones de aprovisionamiento, regulación y culturales se convierten en beneficios y por ende en servicios para el ser humano, tanto o más que en otros ecosistemas (Betancur et al. 2016).

Retomando las iniciativas plasmadas por Naciones Unidas en el programa de Evaluación de Ecosistemas del Milenio (EEM 2005), adoptando el marco de referencia del proyecto UNESCO-IGCP604 para la evaluación de los servicios de los humedales relacionados con el agua subterránea (Bocanegra et al. 2014) y poniendo en evidencia la conexión que existe en Colombia entre acuíferos y áreas de potencial 
humedal, se identificaron y caracterizaron catorce humedales para los cuales se realizó una primera evaluación del estado de los servicios ecosistémicos de regulación, abastecimiento y culturales y los factores de cambio que generan impacto sobre ellos. En este artículo se resumen algunos resultados.

\section{Antecedentes}

Enmarcado en el rumbo de la investigación hidrogeológica en Colombia, la interacción de los humedales con aguas subterráneas constituye una línea emergente de trabajo sobre la que se han desarrollado las primeras investigaciones locales. Entre 2006 y 2010 Colombia hizo parte de un convenio con la Agencia Internacional de Energía Atómica, en el marco del cual se desarrollaron en la Universidad de Antioquia dos tesis de maestría para entender la interacción agua subterránea - humedal, empleando técnicas hidrogeoquímicas, isotópicas y modelación numérica (Santa et al. 2008; Montoya y Gaviria 2011). Abordando el tema de servicios ecosistémicos y su impacto para el bienestar humano, el país participó de una iniciativa de red internacional a través del proyecto UNESCO IGCP 604 Groundwater and Wetlands in Ibero-América en el que el trabajo se realizó principalmente en Argentina, Brasil, Colombia y España. En este se desarrolló y se aplicó una propuesta metodológica para caracterizar los servicios de humedales relacionados con aguas subterráneas; de los sesenta y cuatro casos de estudio documentados en dicho proyecto seis correspondieron a humedales de Colombia (Betancur et al. 2015). Recientemente, para los humedales del río León, asociados al sistema hidrogeológico del Eje Bananero de Urabá, se efectúo una primera aproximación a la valoración de los servicios ecosistémicos (Arana et al. 2015).

Debido a los efectos generados por los fenómenos de La Niña y El Niño, se hizo visible la alta vulnerabilidad que tiene Colombia ante estas circunstancias extremas y fue perentorio definir la implementación de políticas de gestión para garantizar un incremento en la capacidad de adaptación al cambio climático y a la mitigación de sus impactos. Con base en esto, el Gobierno Nacional, a través del Fondo Adaptación, impulsó la implementación de estrategias para la gestión adaptativa y diferencial, que incluyeran acciones sobre los generadores de cambio para disminuir las presiones sobre los humedales y garantizar su integridad ecológica y el suministro de sus servicios ecosistémicos a medio y largo plazo, en funciones tan vitales como el abastecimiento de agua en épocas de escasez. En este sentido, el Instituto de Investigación de Recursos Biológicos Alexander von Humboldt (IAvH), con el apoyo del Fondo de Adaptación, el Ministerio de Ambiente y Desarrollo Sostenible (MADS), el Instituto de Hidrología Meteorología y Estudios Ambientales (Ideam) y el Instituto Geográfico Agustín Codazzi (Igac), han venido generando los insumos técnicos necesarios para la delimitación de ecosistemas estratégicos de páramos y humedales, con el fin de contribuir al fortalecimiento de los procesos de ordenamiento ambiental del territorio.

El IAvH ha inventariado 31.702 humedales y ha aplicado los criterios de delimitación construidos de manera participativa (Vilardy et al. 2014), para entregar en 2015 el primer mapa de humedales de Colombia, a escala 1:100.000 (Flórez et al. 2015). Así mismo, desde el punto de vista biológico el $\mathrm{IAvH}$ ha definido los criterios clave a utilizar para la identificación caracterización y establecimiento de límites de humedales (Lasso et al. 2014), incluyendo su aplicación práctica en las sabanas inundables en la Orinoquia (Osorio-Peláez et al. 2015). Este mapa demarca las zonas de humedal, clasificándolos en las categorías: humedal permanente abierto, humedal permanente bajo dosel, humedal temporal y humedales de potencial medio y potencial bajo.

En materia de aguas subterráneas, el Ideam ha resumido la información hidrogeológica del país en dos publicaciones en las que se incluye el estado del conocimiento sobre sistemas acuíferos: Aguas subterráneas en Colombia: una visión general (Ideam 2013) y el Estudio Nacional del Agua (ENA) (Ideam 2015). 
De la unión de estos dos saberes (humedales e hidrogeología), se identificaron y caracterizaron los sistemas de flujo entre humedales y aguas subterráneas, en el marco de la prestación de servicios ecosistémicos en las unidades de análisis y sitios prioritarios definidos, teniendo en cuenta la disponibilidad de información hidrogeológica y de humedales.

\section{Marco conceptual}

El ciclo hidrológico, entendido como el movimiento continuo del agua en la hidrosfera, conecta los reservorios atmosférico, superficial y subterráneo, incluyendo la biosfera como elemento común de especial interés. Los movimientos de agua desde y hacia la atmósfera están determinados por la precipitación, la evaporación y la transpiración. Como resultado de la infiltración y la recarga se genera la humedad del suelo y se conforma la zona saturada de las unidades hidrogeológicas. Mediante flujos subsuperficiales y subterráneos el agua puede regresar a la superficie para incorporarse a los caudales que de nuevo, en algún momento, regresan a la atmósfera. Al representar el flujo base un aporte de los acuíferos a las fuentes superficiales de agua, él mismo constituye un factor importante en el sostenimiento de muchos ecosistemas acuáticos y terrestres. Así pues, para poder establecer medidas de manejo y protección efectivas es necesario entender el ciclo hidrológico y las relaciones entre sus componentes con una visión integral (Betancur et al. 2016).

\section{Humedales relacionados con el agua subterránea}

Los humedales relacionados con el agua subterránea están generalmente localizados en lugares donde el nivel freático está cerca de la superficie del terreno. En todos ellos, la presencia de agua constituye un factor determinante en el desarrollo de los suelos, la vegetación y el paisaje (Custodio 2010).

Muchos humedales están situados sobre llanuras de inundación o en las riberas de ríos, lagos o estuarios, otros se forman en depresiones cerradas -cuencas endorreicas- en las que se acumula la escorrentía superficial o emerge una descarga de flujo subterráneo, otros aparecen sobre laderas o pendientes en las que la zona saturada corta o queda próxima a la superficie topográfica y da origen a un manantial o a una zona de rezume, o simplemente a una zona de más intensa evapotranspiración. En casi todos los casos los humedales se caracterizan por estar en contacto con una superficie freática muy próxima a la superficie topográfica. Prácticamente las únicas excepciones a esta ley general son las pequeñas depresiones cerradas que quedan colgadas sobre la superficie freática local y constituyen áreas de recarga para el acuífero infrayacente. En estas zonas de recarga los suelos pueden no tener las características hidromórficas típicas de los demás humedales y la zona saturada puede quedar próxima a la superficie topográfica sólo durante un breve periodo de tiempo. Usualmente un descenso regional del nivel de agua en un acuífero dará origen a cambios drásticos en el funcionamiento hidrológico de los humedales relacionados con él. En zonas de clima árido y semiárido, esos humedales dejarán de ser zonas de descarga del acuífero y pasarán a convertirse en zonas de recarga. El descenso generalizado de la superficie freática también suele implicar cambios significativos en las características químicas de las aguas del humedal (Llamas 1993).

Recientemente, el programa para la Evaluación de los Ecosistemas del Milenio de Naciones Unidas (EEM) ha reconocido que el incremento en el uso del agua subterránea en todo el mundo representa un peligro para los humedales relacionados con ellas (Winter et al. 1998, Schot y Winter 2006, McEvan et al. 2006, Wada et al. 2012, Margat y van der Gun 2013).

\section{Aguas subterráneas}

Las aguas subterráneas constituyen más del $97 \%$ del agua líquida dulce disponible en el planeta (Shiklomanov 1997), y cada vez más representan la única fuente segura para abastecimiento humano y para satisfacer las demandas de actividades económicas, especialmente de la agricultura (National 
Groundwater Association 2015). El resultado de la exploración y la investigación es un modelo hidrogeológico conceptual en el que se identifican claramente las condiciones de las distintas unidades hidrogeológicas, sus propiedades hidráulicas y las direcciones de flujo, desde las zonas de recarga, a través del tránsito y hasta las áreas de descarga. Las bases conceptuales de la hidrología subterránea están claramente expuestas en textos clásicos sobre el tema (Custodio y Llamas 1976), y la generación de nuevo conocimiento es permanente. La utilización de más y mejores tecnologías para la exploración del subsuelo y las posibilidades de modelación espacial de grandes volúmenes de información ha posibilitado una continua actualización del conocimiento y el refinamiento de los modelos conceptuales y la necesidad de incorporar el agua subterránea a la gestión integral del recurso hídrico ha abierto nuevos campos de aplicación y proyección a las ciencias hidrogeológicas. No obstante, no deja de reconocerse la necesidad de profundizar en la hidrogeología cuantitativa (Dennehy et al. 2015). Siempre será necesario contar con la existencia de modelos conceptuales validados a escala regional y local, la caracterización de hidroperiodos, la modelación numérica de flujo a distintas escalas (Joyce et al. 2014) y los análisis hidrogeoquímicos e isotópicos (Glynn y Plummer 2005) validan el conocimiento de las fuentes y áreas de recarga, las zonas de tránsito y los sitios descarga de acuíferos. Esta comprensión es crucial para establecer las posibles conexiones de las aguas subterráneas con los humedales.

\section{Servicios ecosistémicos y humedales}

El concepto de servicio ecosistémico ha sido objeto de discusión y análisis durante las últimas décadas. Daily (1997) definió los servicios ecosistémicos como las condiciones y procesos a través de los cuales los ecosistemas naturales y las especies conforman, sostienen y satisfacen la vida humana. En el mismo año, Costanza et al. (1997) se refieren a ellos como los beneficios que las poblaciones humanas derivan directa o indirectamente de las funciones de los ecosistemas. Esta acepción fue retomada en 2005 por Naciones Unidas en el programa sobre la Evaluación de los Ecosistemas del Milenio (EEM 2005), por Boyd y Banzhaf (2007) y por Fisher et al. (2008), entre otros muchos.

En EEM (2005) se consideran tres categorías de servicios: abastecimiento, regulación y culturales. Los servicios de abastecimiento son los productos obtenidos directamente de la estructura biótica, hidrológica y geológica de los ecosistemas; incluyen agua de buena calidad, agua para distintos usos, producción artificial de recursos alimentarios y producción de materias primas, biológicas y minerales.

Los servicios de regulación son los beneficios obtenidos de manera indirecta del funcionamiento de los ecosistemas e incluyen la regulación hídrica, la purificación del agua, el control de la erosión del suelo y el control climático, entre otros. Los servicios culturales son los beneficios intangibles o no materiales que las personas obtienen a través de las experiencias estéticas, educativas, turismo o de enriquecimiento espiritual, entre otras.

Saber cuáles son los factores que provocan cambios en el funcionamiento de los ecosistemas y en los servicios que estos prestan es fundamental para diseñar medidas de manejo e intervenciones que potencien impactos positivos y minimicen los impactos negativos. En este contexto, un "impulsor" es cualquier factor que altere algún aspecto de un ecosistema (EEM 2005).

Los impulsores de cambio pueden ser de origen antrópico, asociados a actividades productivas $\mathrm{y}$ económicas que generan impacto en los humedales, pero también estos impulsores de cambio pueden ser de origen natural, como los son la ocurrencia de procesos naturales de sedimentación, colmatación e influencia de factores cambiantes como la precipitación y la temperatura en el área del humedal. De acuerdo con EEM (2005), los principales impulsores de cambios en el funcionamiento y los servicios de los humedales son la explotación intensiva de recursos, los cambios de uso del suelo, la modificación del ciclo hidrológico, la contaminación, los efectos asociados a cambios y el cambio climático y global. 
La explotación intensiva de recursos incluye la extracción de agua del humedal y de las masas de agua a las que está vinculado -incluyendo los acuíferos-, y la explotación biológica y la obtención de minerales en sus diversas formas. Los cambios en el uso de suelo tratan de los efectos sobre los humedales relacionados con los aspectos de deforestación, agricultura, ganadería y urbanización, entre otros. El factor de modificación del ciclo hidrológico toma en cuenta tanto aquellos cambios en la red de flujo de la cuenca del humedal que influyen sobre la hidrología de éste, como los cambios en los flujos de entrada, salida y la variación de almacenamiento del propio humedal. La contaminación del humedal se asocia fundamentalmente a la contaminación difusa agrícola y atmosférica, y a procesos puntuales de origen urbano e industrial. Los efectos asociados a cambios contemplan alteraciones en la calidad mineral y biológica del agua y otros efectos en el suelo. Y finalmente, los factores de interés vinculados al cambio climático y global son las variaciones en la precipitación y en la temperatura y el aumento del nivel del mar (Betancur et al. 2016).

Los humedales están entre los ecosistemas del planeta más amenazados en los últimos 50 años; así mismo, la utilización humana de la mayoría de los servicios que proveen se está incrementando y están siendo degradados (Carpenter et al. 2009). Es por esto que el estudio de la relación de los humedales con las aguas subterráneas y de los servicios que dicha relación soporta, cobra importancia de cara a la gestión sostenible de los ecosistemas de humedal.

\section{Materiales y métodos}

La relación entre acuíferos y humedales se establece a partir de la superposición espacial de mapas que caractericen ambos sistemas hidrológicos. La extensión de de y los sistemas de flujo subterráneo, indican rutas y conexiones entre aguas superficiales y subterráneas. Una clara definición de los humedales y la aplicación de criterios precisos para su delimitación constituye un procedimiento fundamental para establecer de manera argumentada las fronteras de la interconexión. En Colombia se desarrolló una metodología para la identificación de la relación entre humedales y agua subterránea, en el marco del convenio entre la Universidad de Antioquia y el Instituto de Investigación de Recursos Biológicos Alexander von Humboldt, sobre el cual trata este artículo.

El programa de Evaluación de los Ecosistemas del Milenio ha propuesto mecanismos para identificar y evaluar los servicios ecosistémicos de los humedales. La aplicación de esos criterios permite identificar, en el contexto de la relación agua superficial-agua subterránea, la importancia de la vinculación entre ellos.

El recorrido de esta ruta metodológica (Figura 1) puede llevarse a cabo siempre y cuando se cuente con información documentada. Esta representa el primer e indispensable insumo para la ejecución de cualquier intento por establecer dependencia humedal - agua subterránea. La claridad en los procedimientos constituye el argumento para definir los caminos de selección y priorización de sistemas a evaluar y el disponer de un instrumento adecuado para la síntesis de información representa la clave del éxito en este propósito. 


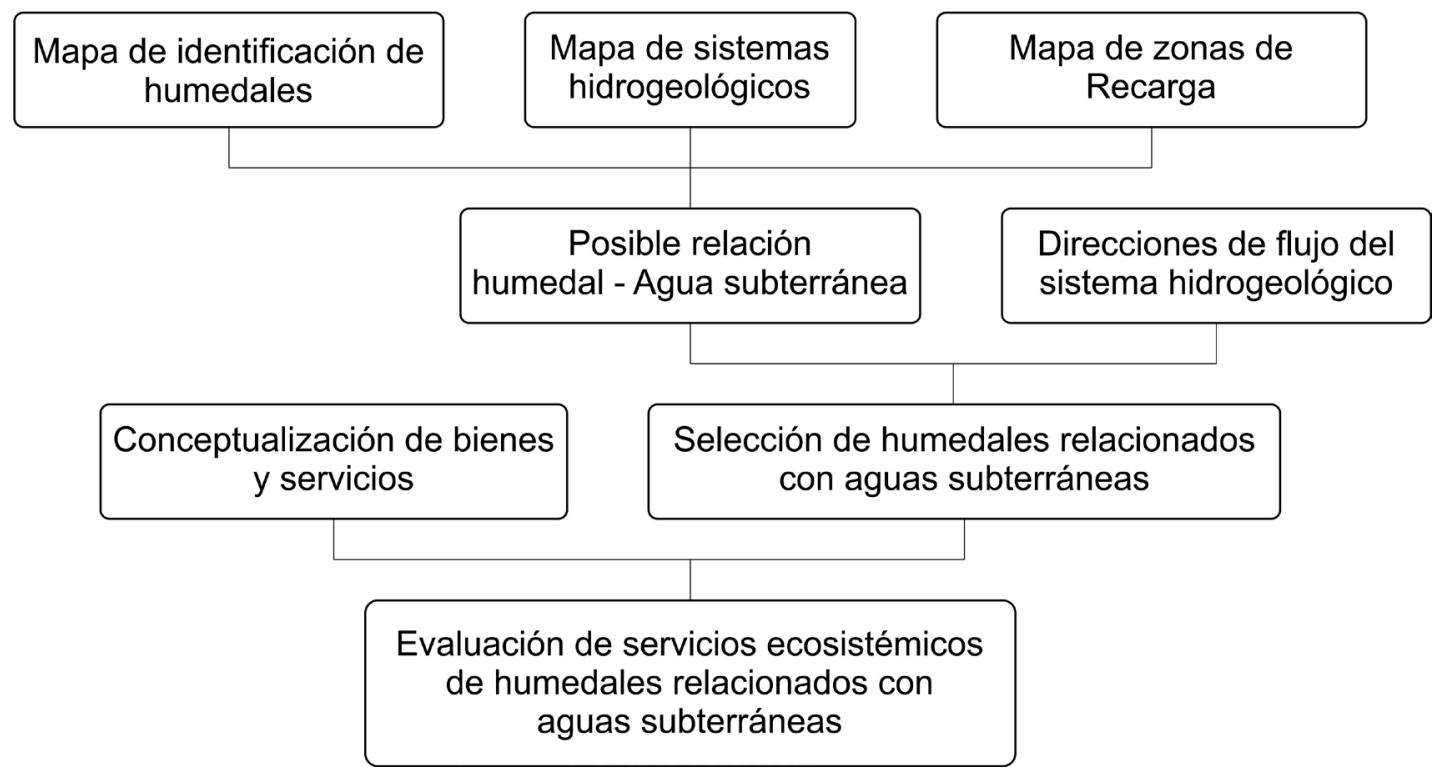

Figura 1. Esquema metodológico para la identificación de humedales relacionados con el agua subterránea y la evaluación de servicios ecosistémicos en ellos.

\section{Información documentada}

En el mapa de la figura 2 se representan las áreas de humedal identificadas por Flórez et al. (2015) para Colombia; cubren 30.781.149 ha, que corresponden al $26,99 \%$ de la superficie continental del país; la mayor extensión corresponde a humedales temporales (58 $\%)$, seguido de las áreas de potencial medio (16,3\%). Es importante señalar que el $92 \%$ de los humedales inventariados por el IAvH (31.702), se localizan sobre las zonas identificadas en el mapa.

Existe poca información disponible acerca de las caracterizaciones hidrológica, física o biológica de los humedales en el país. La documentación de los casos de estudio seleccionados para este primer ejercicio nacional de establecimiento de la relación entre humedales y aguas subterráneas se logró gracias a la colaboración de varias entidades nacionales, que atendieron la solicitud y suministraron los estudios que habían adelantado: la Corporación Autónoma Regional del Quindío (CRQ) (Leguizamón 2010), la Corporación Autónoma Regional de la Meseta de
Bucaramanga (CDMB), la Corporación Autónoma Regional del Tolima (Cortolima), la Corporación Autónoma Regional para el Desarrollo de Urabá (Corpourabá) (Corpourabá 2013, Universidad de Medellín y Corpourabá 2014), la Corporación Autónoma Regional del Centro de Antioquia (Corantioquia) (Corantioquia2005, Corantioquia y Corporación Montañas 2005, 2006); Universidad de Antioquia (Santa 2010, Montoya 2010, Gómez 2010). El acceso a otras fuentes de información se logró mediante consultas y selección de material en las páginas web de entidades oficiales y centros de documentación. A través de ellas se pudo conocer el estado del conocimiento de los humedales: Buenavista en La Guajira (Invemar et al. 2009), Cabezón (CVC y Funecorobles s.f.) y Timbique (Fundalimento 2005) en el Valle del Cauca, Ciénagas de la región Panzenú (Corantioquia y Neotrópicos 2000, 2001), Humedales en la Sabana de Bogotá (UNAL e IDEA 2006, Adessa y EAAB 2006, Universidad Pontificia Javeriana y EAAB 2009), Lago Sochagota en Sogamoso (UIS 


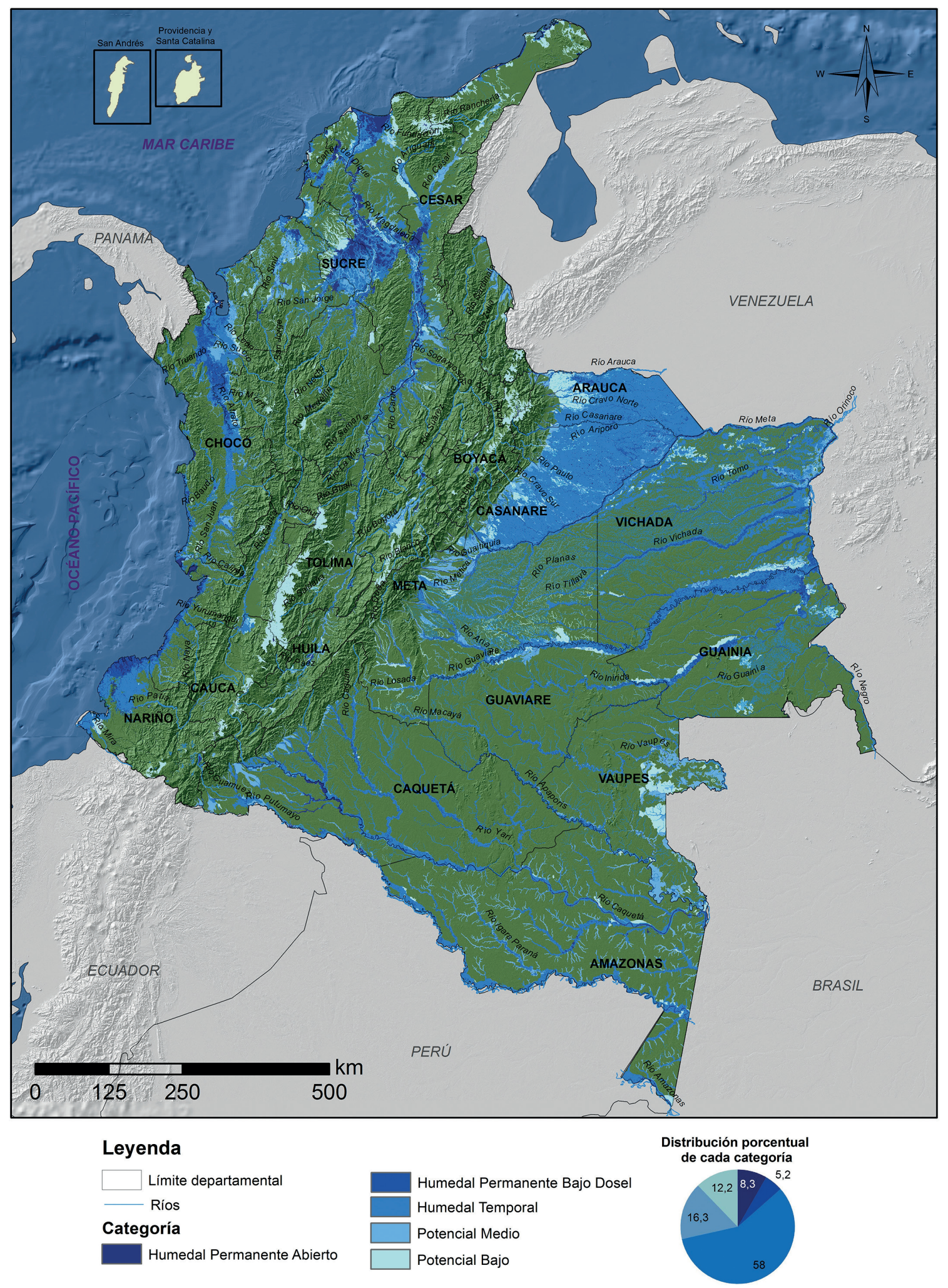

Figura 2. Mapa de humedales del IAvH y distribución porcentual de las categorías según áreas (Adaptado de Flórez et al. 2015). 
2010), Laguna del Otún en Risaralda (CARDER y Parques Nacionales Naturales de Colombia 2013), Complejo Papayal en Rionegro Santander (CDMV 2010).

En sus publicaciones sobre las aguas subterráneas en Colombia y el Estudio Nacional del Agua, el Ideam (2013 y 2015) ha reunido una gran cantidad de información procedente de diferentes estudios realizados por muchos autores y entidades en el país. De esta forma se logró sintetizar un estado del conocimiento sobre los sistemas hidrogeológicos. De acuerdo con el panorama que presenta el Ideam, más del $75 \%$ del territorio colombiano está sin explorar en materia de hidrogeología y existe un conocimiento desigual para 61 sistemas acuíferos reconocidos; 27 de esos acuíferos tendrían un nivel de conocimiento adecuado y 73 no cuentan con un nivel de conocimiento adecuado. Las zonas menos estudiadas se localizan en las áreas hidrográficas del Pacífico, Orinoco y Amazonas.

Para algunos casos específicos se logró trascender hacia un mayor detalle los alcances de los estudios del Ideam y se tuvo acceso a modelos hidrogeológicos a escala 1:25.000. Estos casos corresponden a los sistemas hidrogeológicos de la cuenca del río Ranchería (Duque et al. 2014), el bajo Cauca antioqueño (Betancur 2014) y el Eje Bananero de Urabá (Villegas et al. 2013).

La información hidrogeológica se complementó con la caracterización de las zonas de recarga. Una delimitación parcial y preliminar de ellas ha sido realizada por el Servicio Geológico de Colombia (SGC) (SGC 2013).

\section{Criterios de priorización y síntesis de información según fichas IGCP}

Para seleccionar los humedales a ser analizados, inicialmente se superpusieron los sistemas hidro- geológicos con información suficiente y aceptable (Ideam 2013) y el mapa de zonas de recarga del Servicio Geológico Colombiano, con el inventario de humedales y el mapa de humedales del IAvH (Flórez et al. 2015). Posteriormente a este ejercicio de identificación se aplicó un filtro para seleccionar los humedales que habiendo sido objeto de algún estudio al que se pudiera acceder, contaran con un nivel de conocimiento que se pudiera considerar aceptable para los propósitos del trabajo. Se consideró deseable poder analizar humedales ubicados en diferentes ambientes geográficos. Teniendo en cuenta estas consideraciones, se eligió el conjunto de humedales que se ajustaban a los requerimientos necesarios para cumplir con los objetivos del proyecto.

Para la evaluación de los servicios que prestan los humedales relacionados con las aguas subterráneas seleccionados mediante los criterios de priorización, se implementó la metodología del proyecto UNESCO IGCP 604, dentro de la cual, para evaluar las interacciones aguas subterráneas-humedalesbienestar humano en Iberoamérica, se diseñó una ficha en la que se diligencia, para cada humedal, información correspondiente a aspectos generales, estado de los servicios del humedal y factores que inducen cambios en los servicios ecosistémicos.

También se contó con un formato o ficha síntesis en la que, aplicando las convenciones propuestas por (EEM 2005), se emplea un código estilo semáforo para poder evaluar y comparar el estado de los servicios; dicho código propone el uso del color verde para representar un servicio Alto, amarillo para la categoría Medio y rojo para un servicio Bajo. También a los factores impulsores de cambios sobre los servicios ecosistémicos se les aplica un código de colores: rojo para un impacto Alto en los servicios del humedal, amarillo si el impacto es Moderado y verde cuando el factor perturba a un nivel Bajo. Las figuras 3 y 4 representan el estilo de las fichas síntesis para la identificación de servicios e impactos. 


\begin{tabular}{|c|c|c|c|c|c|c|c|c|c|c|c|c|c|c|c|c|c|}
\hline \multirow[t]{2}{*}{ Nombre y Pais } & \multirow[t]{2}{*}{ Tipo } & \multicolumn{7}{|c|}{ ABASTECIMIENTO } & \multicolumn{4}{|c|}{ REGULACIÓN } & \multicolumn{5}{|c|}{ CULTURALES } \\
\hline & & 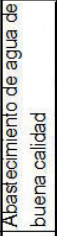 & 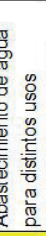 & 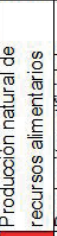 & 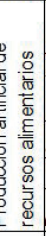 & 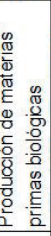 & 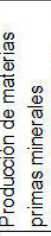 & 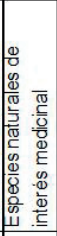 & 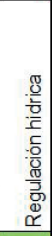 & 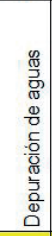 & 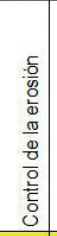 & 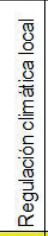 & $\begin{array}{l}0 \\
0.0 \\
\frac{.0}{5} \\
\frac{5}{5} \\
⺊\end{array}$ & 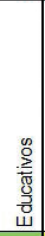 & 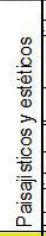 & 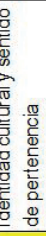 & 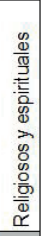 \\
\hline $\begin{array}{c}\text { Sabana de Bogotá, } \\
\text { Colombia }\end{array}$ & $2 \mathrm{aB}$ & $\rightarrow$ & $\pi$ & ע & $\rightarrow$ & $\rightarrow$ & $\rightarrow$ & $\rightarrow$ & $\rightarrow$ & ע & $\rightarrow$ & $\rightarrow$ & $\pi$ & $\pi$ & $\pi$ & $\rightarrow$ & \\
\hline \multirow[t]{7}{*}{ Cabezón, Colombia } & $1 \mathrm{dQ}$ & $\rightarrow$ & $\rightarrow$ & $\rightarrow$ & $\rightarrow$ & $\rightarrow$ & & & ע & $\rightarrow$ & & $\rightarrow$ & $\rightarrow$ & $\rightarrow$ & ע & $\rightarrow$ & \\
\hline & & & & \multicolumn{4}{|c|}{ Estado del servicio } & \multicolumn{5}{|c|}{ Tendencia del servicio } & & & & & \\
\hline & & & & & \multicolumn{3}{|c|}{ Alto } & $\uparrow$ & \multicolumn{4}{|c|}{ Mejora del servicio } & & & & & \\
\hline & & & & & \multicolumn{3}{|c|}{ Medio } & $\pi$ & \multicolumn{4}{|c|}{ Tendencia a mejorar } & & & & & \\
\hline & & & & & \multicolumn{3}{|c|}{ Bajo } & $\rightarrow$ & \multicolumn{4}{|c|}{ Tendencia estable } & & & & & \\
\hline & & & & & \multicolumn{3}{|c|}{ Inexistente } & ע & \multicolumn{4}{|c|}{ Tendencia a empeorar } & & & & & \\
\hline & & & & & \multicolumn{3}{|c|}{ Desconocido } & $\downarrow$ & \multicolumn{4}{|c|}{ Empeora el servicio } & & & & & \\
\hline
\end{tabular}

Figura 3. Ficha síntesis para la caracterización de los servicios ecosistémicos, su estado y su tendencia.

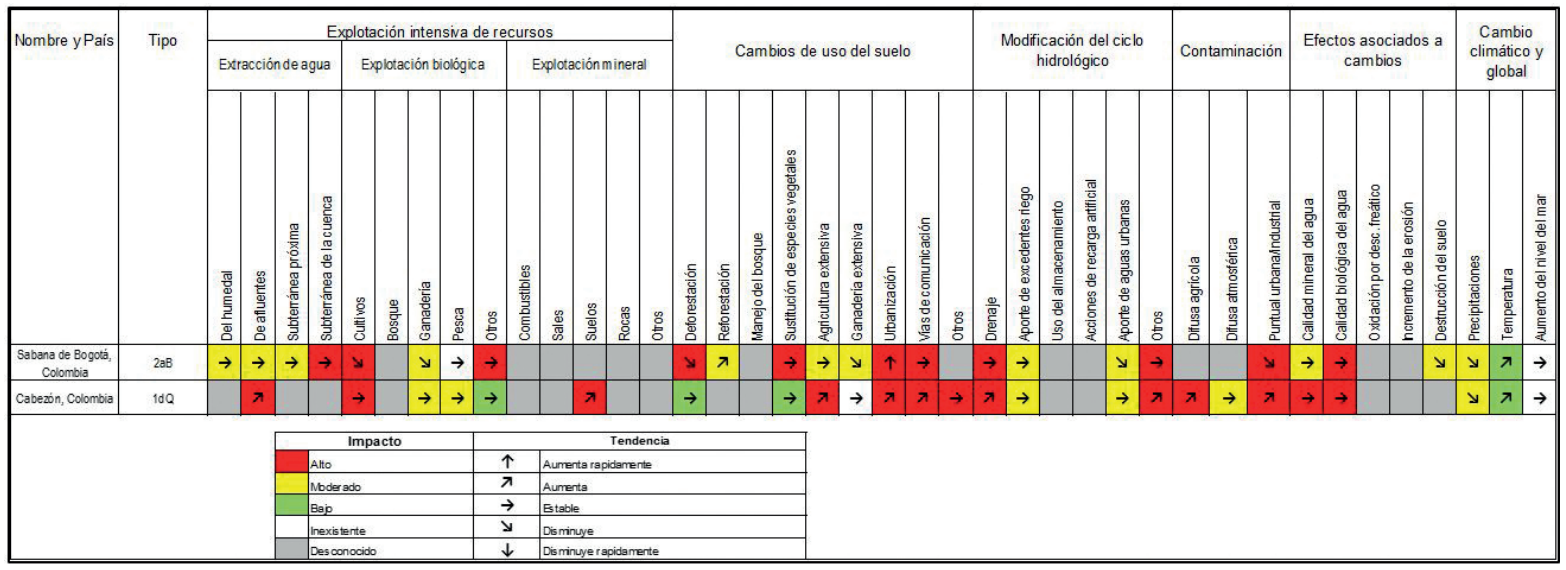

Figura 4. Ficha síntesis para la caracterización de los factores impulsores de cambio sobre los servicios, su estado y su tendencia.

\section{Resultados y discusión}

Inicialmente se presentan los resultados que conciernen a la identificación de la relación entre aguas subterráneas y humedales vinculados a ellas en zonas de recarga, tránsito o descarga; para cada una de estas condiciones se ilustra un caso de estudio representativo. Respecto a la evaluación de servicios ecosistémicos y factores impulsores de impacto, se consideran los catorce humedales identificados en este estudio, haciendo énfasis en los aspectos que tienen que ver con su vinculación con las aguas subterráneas (Figura 5 y Tabla 1). Es necesario señalar que los humedales que se citan en este trabajo no representan los únicos que tienen la condición de estar relacionados con acuíferos en Colombia; ellos constituye los pocos que cumplían los criterios de selección para ser analizados luego de superponer la escasa información hidrogeológica adecuada y sobre conocimiento de los humedales con que se cuenta en el país. 


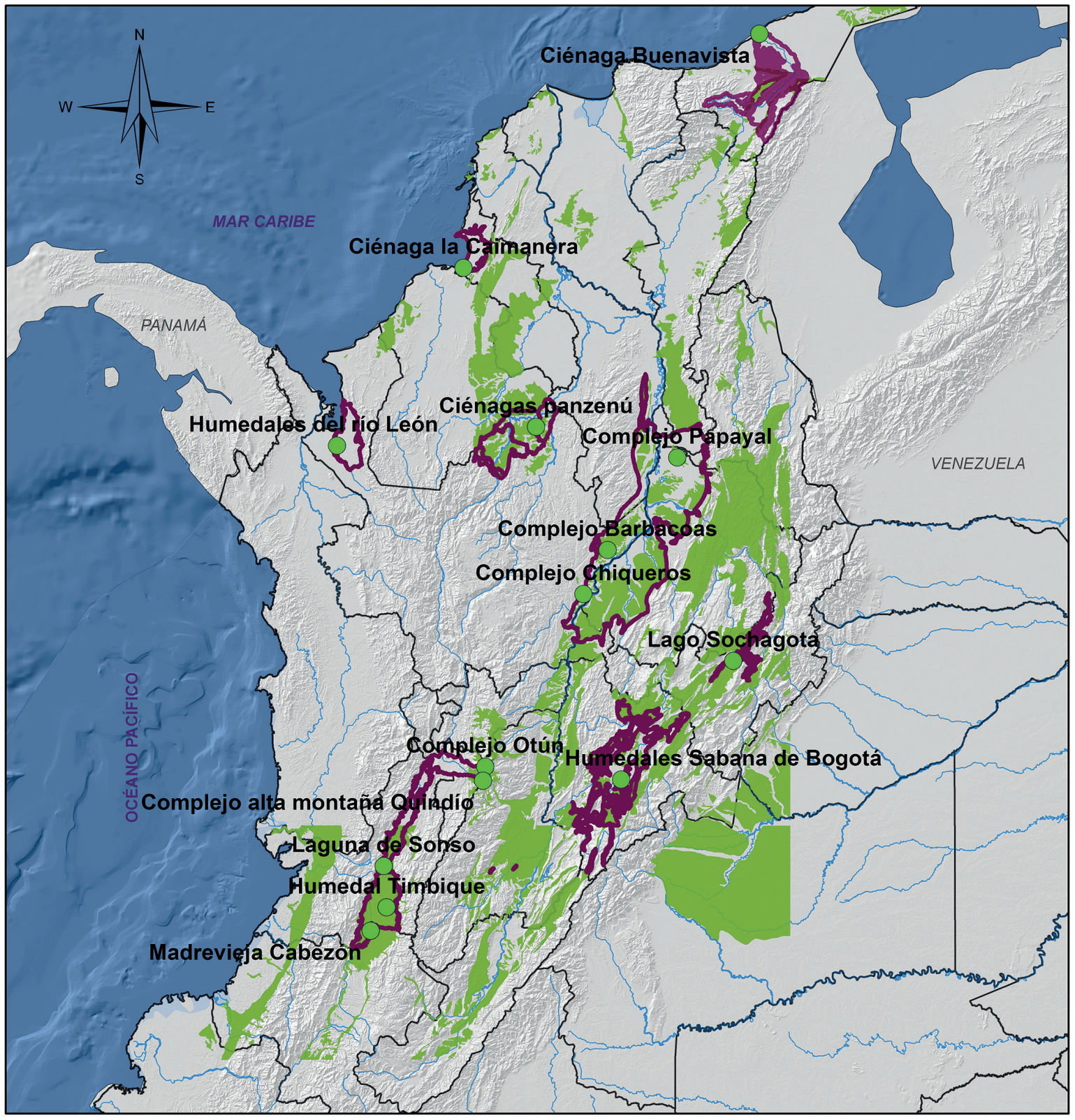

\section{Leyenda}

$\square$ Límite departamental

Ríos
Acuíferos

Zonas de recarga

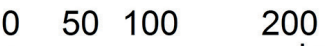

- Humedales/Complejos de humedales

Figura 5. Humedales relacionados con aguas subterráneas en Colombia considerados en este estudio. 
Tabla 1. Humedales vinculados con sistemas hidrogeológicos con información aceptable.

\begin{tabular}{|c|c|c|}
\hline Complejo/conjunto & $\begin{array}{c}\text { Zona hidrográfica / Subzona } \\
\text { hidrográfica }\end{array}$ & $\begin{array}{c}\text { Acuífero/Relación con agua } \\
\text { subterránea }\end{array}$ \\
\hline Laguna de Sonso, Valle del Cauca & Cauca / Ríos Guadalajara y San Pedro & \multirow{3}{*}{$\begin{array}{l}\text { Acuífero del Valle del Cauca, } \\
\text { Zona de recarga }\end{array}$} \\
\hline Humedal Timbique, Valle del Cauca & $\begin{array}{l}\text { Cauca / Río Guachal } \\
\text { (Bolo - Fraile y Párraga) }\end{array}$ & \\
\hline Madrevieja Cabezón Valle del Cauca & Cauca / Ríos Claro y Jamundí & \\
\hline Río León, Urabá - Antioquia & Caribe - Litoral / Río León & Acuífero de Urabá \\
\hline $\begin{array}{l}\text { Sistema de humedales } \\
\text { de la Sabana de Bogotá }\end{array}$ & Alto Magdalena / Río Bogotá & Acuífero de la Sabana de Bogotá \\
\hline $\begin{array}{l}\text { Ciénaga la Caimanera, } \\
\text { Coveñas - Sucre }\end{array}$ & $\begin{array}{l}\text { Caribe - Litoral / Directos Caribe Golfo } \\
\text { de Morrosquillo }\end{array}$ & Acuífero Golfo de Morrosquillo \\
\hline $\begin{array}{l}\text { Lago Sochagota, Duitama, } \\
\text { Sogamoso - Boyacá }\end{array}$ & Sogamoso / Río Chicamocha & Acuífero Duitama Sogamoso \\
\hline $\begin{array}{l}\text { Ciénaga Buenavista, } \\
\text { Manaure - Guajira }\end{array}$ & Caribe - Guajira / Río Ranchería & $\begin{array}{c}\text { Acuífero de la Cuenca río } \\
\text { Ranchería }\end{array}$ \\
\hline Humedales de la región Panzenú & $\begin{array}{l}\text { Nechí / Directos al Cauca entre Pto. } \\
\text { Valdivia y Bajo Nechí }\end{array}$ & $\begin{array}{l}\text { Acuífero del Bajo Cauca } \\
\text { Antioqueño, Zona de recarga }\end{array}$ \\
\hline $\begin{array}{c}\text { Complejo Otún, } \\
\text { Santa Rosa de Cabal - Risaralda }\end{array}$ & $\begin{array}{l}\text { Cauca / Río Otún } \\
\text { y otros directos al Cauca }\end{array}$ & $\begin{array}{l}\text { Acuífero Glacis del Quindío, } \\
\text { Zona de recarga }\end{array}$ \\
\hline $\begin{array}{l}\text { Complejo Papayal, } \\
\text { Rionegro - Santander }\end{array}$ & $\begin{array}{l}\text { Medio Magdalena / Río Lebrija y otros } \\
\text { directos al Magdalena }\end{array}$ & \multirow{3}{*}{$\begin{array}{l}\text { Acuífero Valle medio del } \\
\text { Magdalena, Zona Recarga }\end{array}$} \\
\hline $\begin{array}{l}\text { Complejo Barbacoas, } \\
\text { Yondó - Antioquia }\end{array}$ & $\begin{array}{l}\text { Medio Magdalena / Río Cimitarra y } \\
\text { otros directos al Magdalena }\end{array}$ & \\
\hline $\begin{array}{l}\text { Complejo Chiqueros, } \\
\text { Puerto Berrío - Antioquia }\end{array}$ & $\begin{array}{l}\text { Medio Magdalena / Río San Bartolo y } \\
\text { otros directos al Magdalena Medio }\end{array}$ & \\
\hline $\begin{array}{l}\text { Complejo zona de alta montaña del río } \\
\text { Quindío, Salento, Pereira - Quindío }\end{array}$ & Cauca / Río La vieja & $\begin{array}{c}\text { Acuífero Glacis del Quindío } \\
\text { y Zonas de recarga }\end{array}$ \\
\hline
\end{tabular}

\section{Humedales y zonas de recarga de acuíferos}

Producto de la superposición de las zonas de recarga difusa de los 61 sistemas hidrogeológicos reconocidos por el Ideam, con las áreas de humedal identificadas por el IAvH, se comprueba que $18 \%$ de estas (5.490.639 ha) se localizan en áreas a través de las cuales ingresa agua a los acuíferos (Figura 6). La distribución de las categorías de las áreas de humedales ubicadas en zonas de recarga directa comprenden: humedal temporal $(40 \%)$, potencial bajo $(21,8 \%)$ y potencial medio $(19,1 \%)$.

Asumiendo desde el mapa del SGC las áreas que aportan regionalmente agua subterránea a los acuíferos que configuran sistemas de flujos regionales, se encuentra que $8 \%$ de las áreas de humedales (2.433.930 ha) se ubican dentro de ellas (Figura 7). Las categoría con mayor representatividad para estas zonas corresponden a potencial bajo $(39,3 \%) \mathrm{y}$ humedal permanente abierto $(38,6 \%)$.

El conjunto de humedales de la cuenca alta del rio Quindío y la Laguna del Otún se ubican en áreas de recarga del sistema hidrogeológico Glacis del Quindío, localizado entre el centro y el oriente del departamento de Risaralda (Figura 8). 


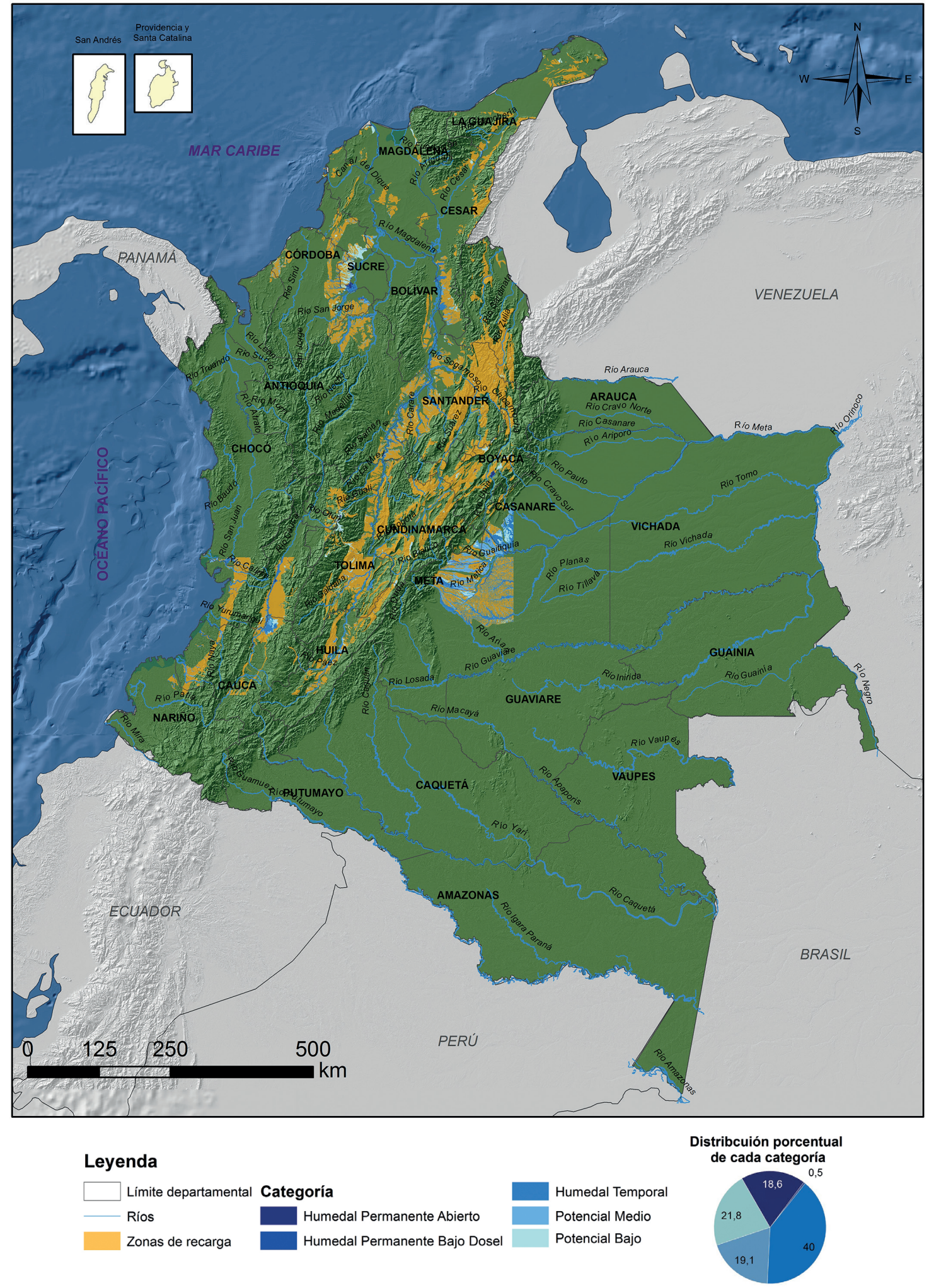

Figura 6. Humedales sobre zonas de recarga y distribución porcentual de las categorías según áreas. 


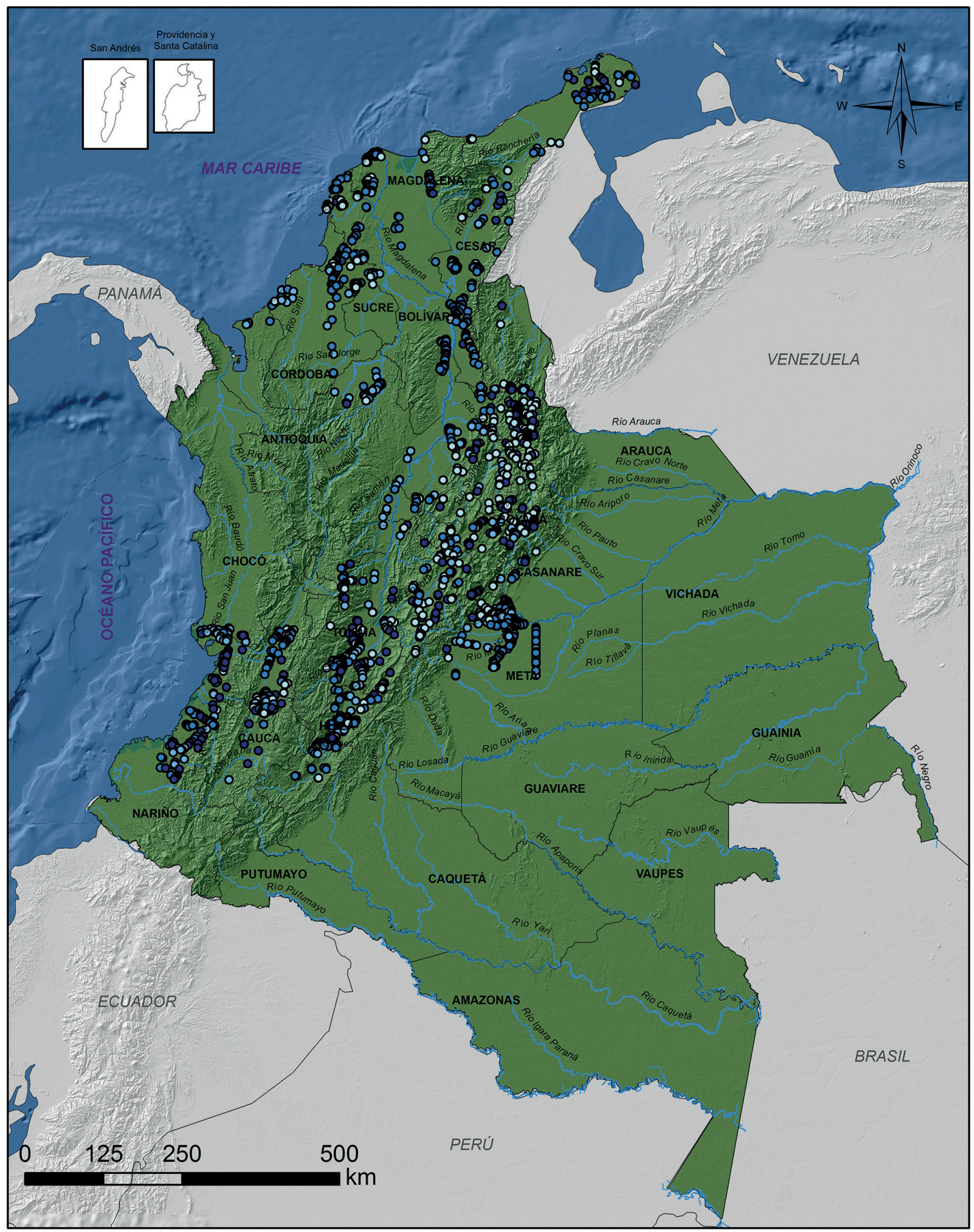

\section{Leyenda}

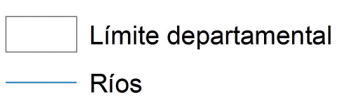

Categoría
- Humedal Permanente Bajo Dosel

- Humedal Temporal

- Potencial Medio

- Potencial Bajo

Figura 7. Humedales sobre zonas de recarga que aportarían flujos regionales. 

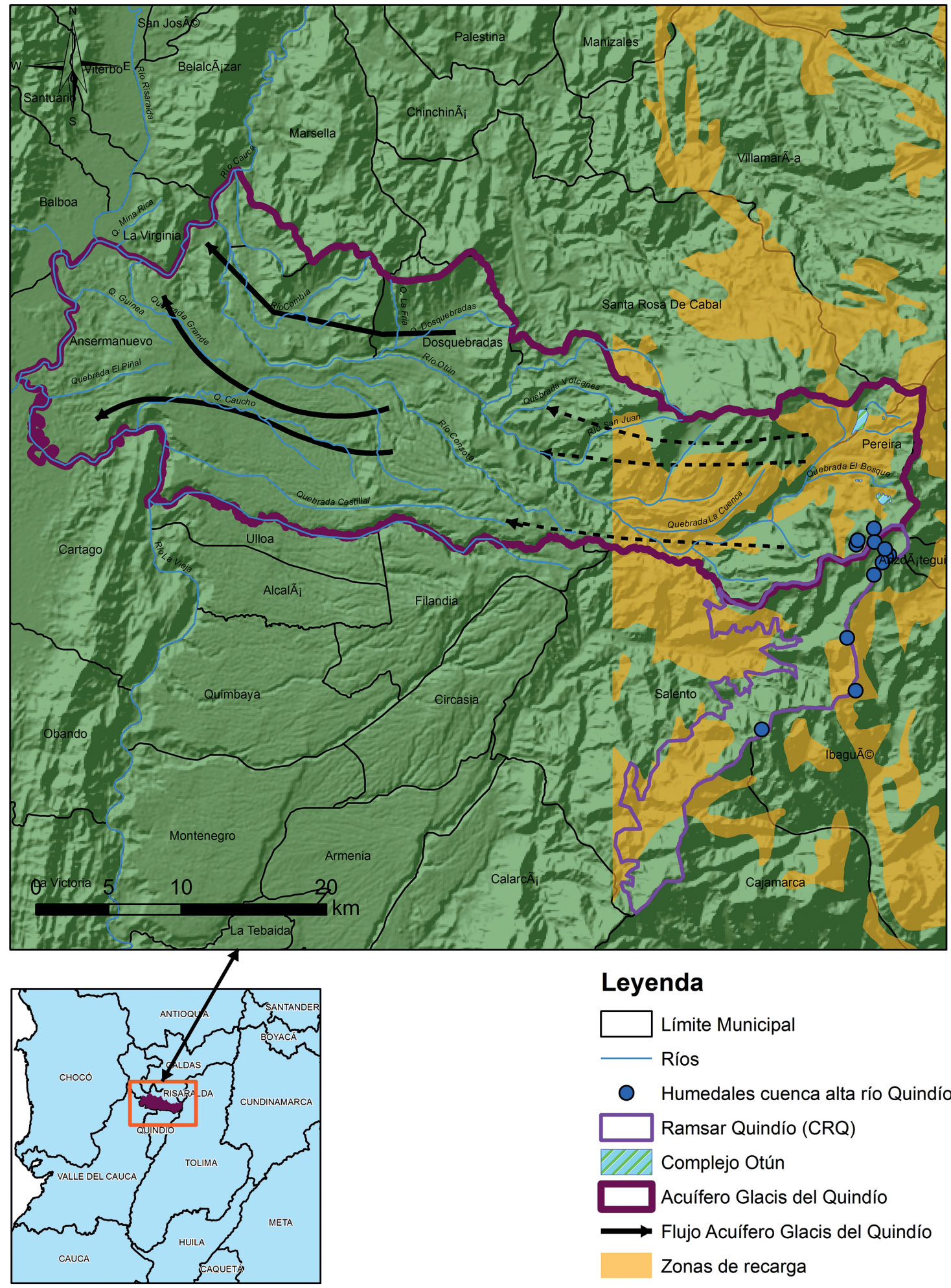

\section{Leyenda}

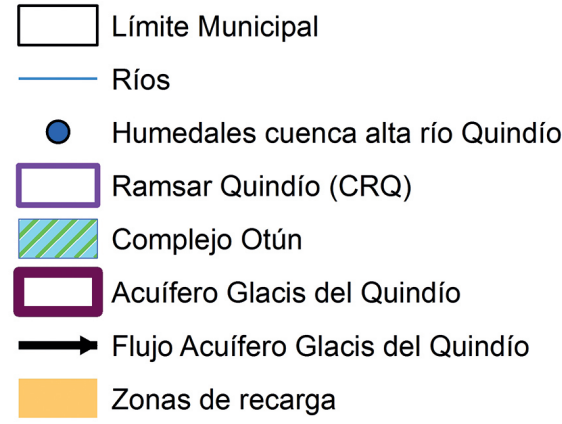

Figura 8. Complejo laguna del Otún, complejo cuenca alta del río Quindío, acuífero Glacis del Quindío y zonas de recarga. 
Según el Ideam (2013), el acuífero del Glacis del Quindío está compuesto por cinco unidades hidroestratigráficas denominadas A1, A2, A3, B1, $\mathrm{B} 2$, donde el acuífero más productivo es el $\mathrm{A} 1$, que es de extensión local y está asociado a las formaciones zarzal y aluviales del río Cauca y río La Vieja; muestra un flujo preferencial en sentido este-oeste desde las zonas altas de recarga hasta descargar las aguas subterráneas en los ríos antes mencionados.

Según la información suministrada por la CRQ (Leguizamón 2010), el conjunto de humedales de la cuenca alta del río Quindío corresponden a un complejo de charcos y pantanos de alta montaña, con una precipitación media de $1500 \mathrm{~mm} /$ año y una temperatura media de $14,6{ }^{\circ} \mathrm{C}$, donde predomina el bosque alto andino. En general los servicios ecosistémicos de este complejo están en un estado alto y el más importante es el de abastecimiento de agua de buena calidad; los factores que más impactan su entorno son la deforestación e introducción de especies maderables y la expansión de la frontera ganadera y agrícola. La laguna del Otún, donde predomina el bosque altoandino y la vegetación de páramo, presta servicios en un estado alto y la actividad más impactante es la ganadería extensiva. La explotación intensiva de aguas subterráneas podría producir descensos en el nivel freático, amenazado la funcionalidad de la laguna.

\section{Humedales y zonas de tránsito de aguas subterráneas}

La coincidencia espacial que se registra entre la localización de los 61 sistemas hidrogeológicos identificados en Colombia por Ideam $(2013,2015)$ y las áreas de humedales definidas por IAvH (Figura 9), es contundente para evidenciar la relación entre estos dos componentes del sistema hidrológico nacional. Del total de las zonas de humedales, se encuentra que el 23,6 \% (7.226.440 ha) se ubica sobre los sistemas hidrogeológicos identificados. Puede constatarse que la mayor cobertura está en la categoría de humedal temporal, con el 49,8\% (3.595.920 ha), seguido de potencial medio con $23,4 \%$ (1.694.390 ha).
Para ilustrar la interacción humedal - agua subterránea en zonas de tránsito, se exponen los casos de los acuíferos del Eje Bananero de Urabá (Figura 10) y del Valle del Cauca (Figura 11).

Si se comparan las áreas de humedal en relación con la extensión del sistema hidrogeológico del Eje Bananero de Urabá (120.800 ha), se encuentra que el $61,2 \%$ de la superficie del acuífero está cubierta por diferentes categorías de áreas de humedal, predominando la condición de potencial medio (58.580 ha). Este sistema hidrogeológico, ubicado en una de las zonas económicas más importantes para el departamento de Antioquia, está compuesto por un acuífero libre de extensión local y un acuífero multicapa confinado del cual captan agua la mayoría de los pozos profundos que utilizan las fincas productoras de banano; el sentido de flujo de agua subterránea describe una trayectoria desde la margen oriental en la serranía de Abibe hacia el río León, en el extremo occidental del acuífero y la costa del mar Caribe al norte (Corpourabá y Universidad de Antioquia 2013).

El humedal Timbique es otro caso en el cual se verifica la ubicación del ecosistema en zonas de tránsito de aguas subterráneas (Figura 11). El acuífero del Valle del Cauca está compuesto por tres unidades denominadas A, B y C; la A corresponde a un acuífero libre, la B a un acuitardo como capa confinante y la $\mathrm{C}$ es menos conocida pero con características de calidad del agua adecuada para el abastecimiento de agua potable. La dirección del flujo en el sistema hidrogeológico configura una trayectoria desde las vertientes de la cordillera Central hacia el río Cauca y se tornan paralelas al río en sus inmediaciones (Ideam 2013). Este humedal se encuentra ubicado al sureste del acuífero del Valle del Cauca y está sometido a condiciones de alta presión antrópica, al estar afectado por el vertimiento de aguas residuales domésticas $\mathrm{y}$ de residuos de la industria azucarera y por la expansión de la frontera agrícola; se ha constatado que la explotación de un pozo cercano provoca el descenso del nivel freático, generando mayor deterioro sobre el humedal (Fundalimento 2005). 


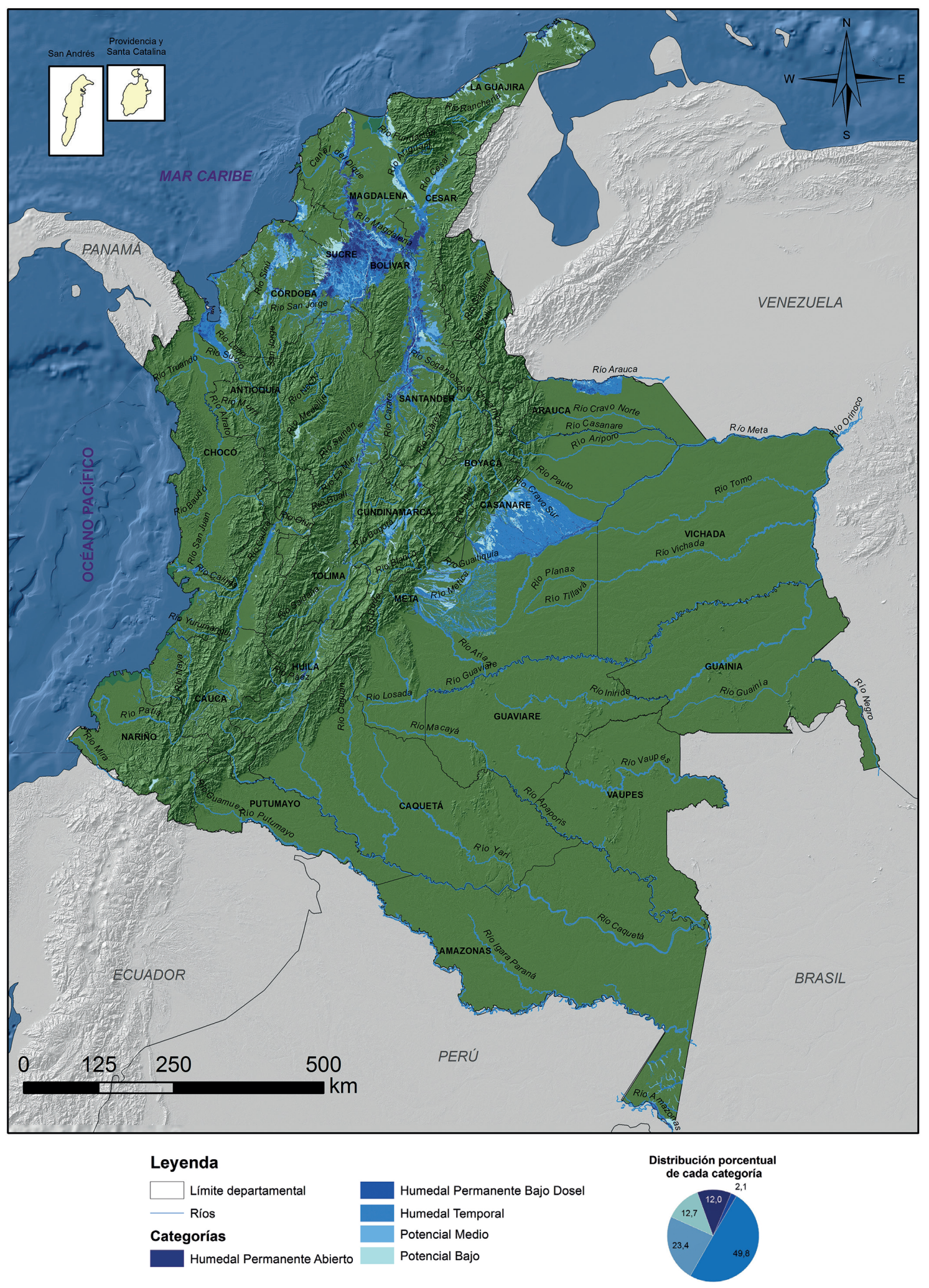

Figura 9. Humedales sobre los sistemas hidrogeológicos de Colombia recopilados por el Ideam (2015) y distribución porcentual por categorías según áreas. 


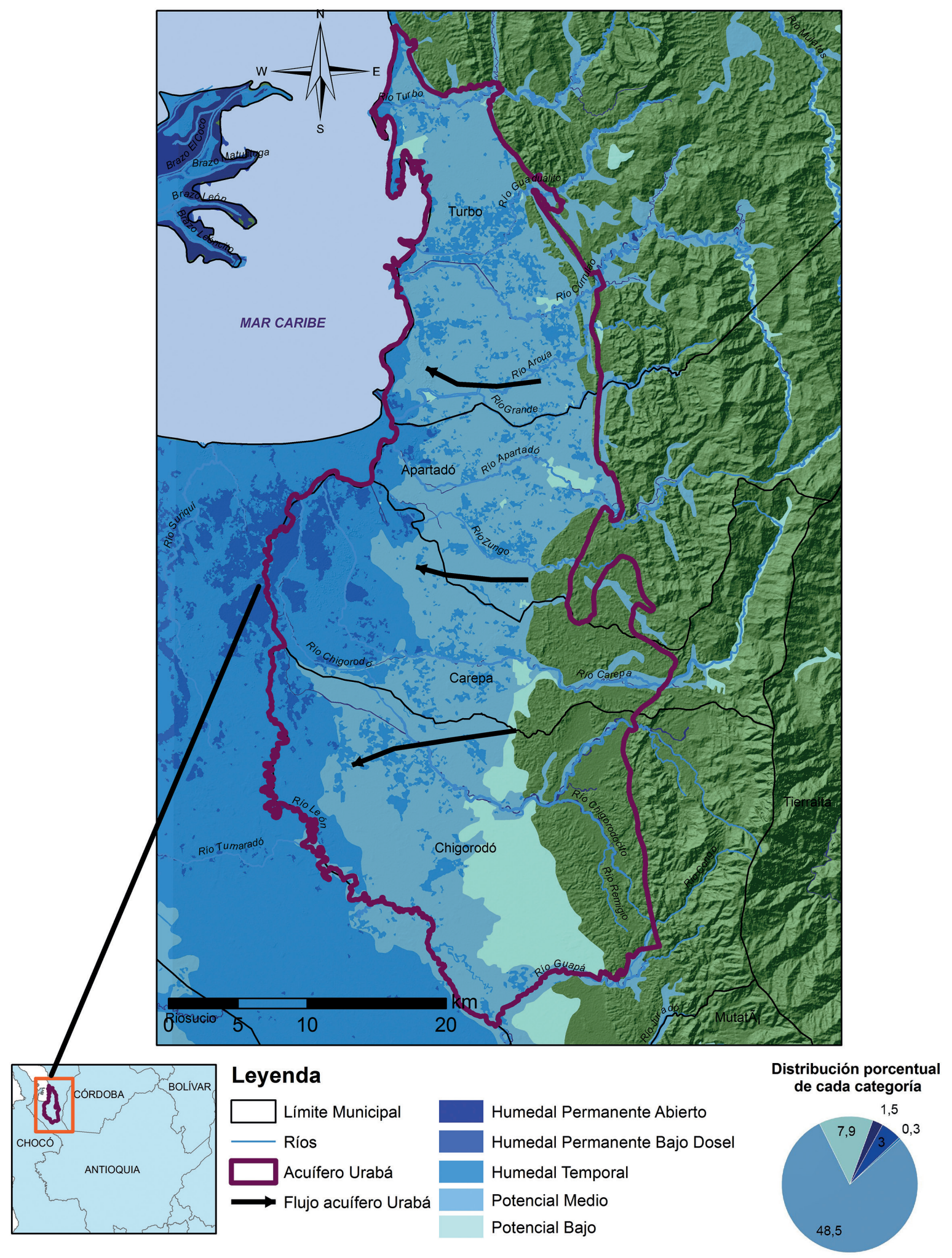

Figura 10. Zonas de humedales relacionados con zonas de tránsito de aguas subterráneas en el acuífero del Golfo de Urabá y distribución de las áreas de humedal respecto al acuífero. 


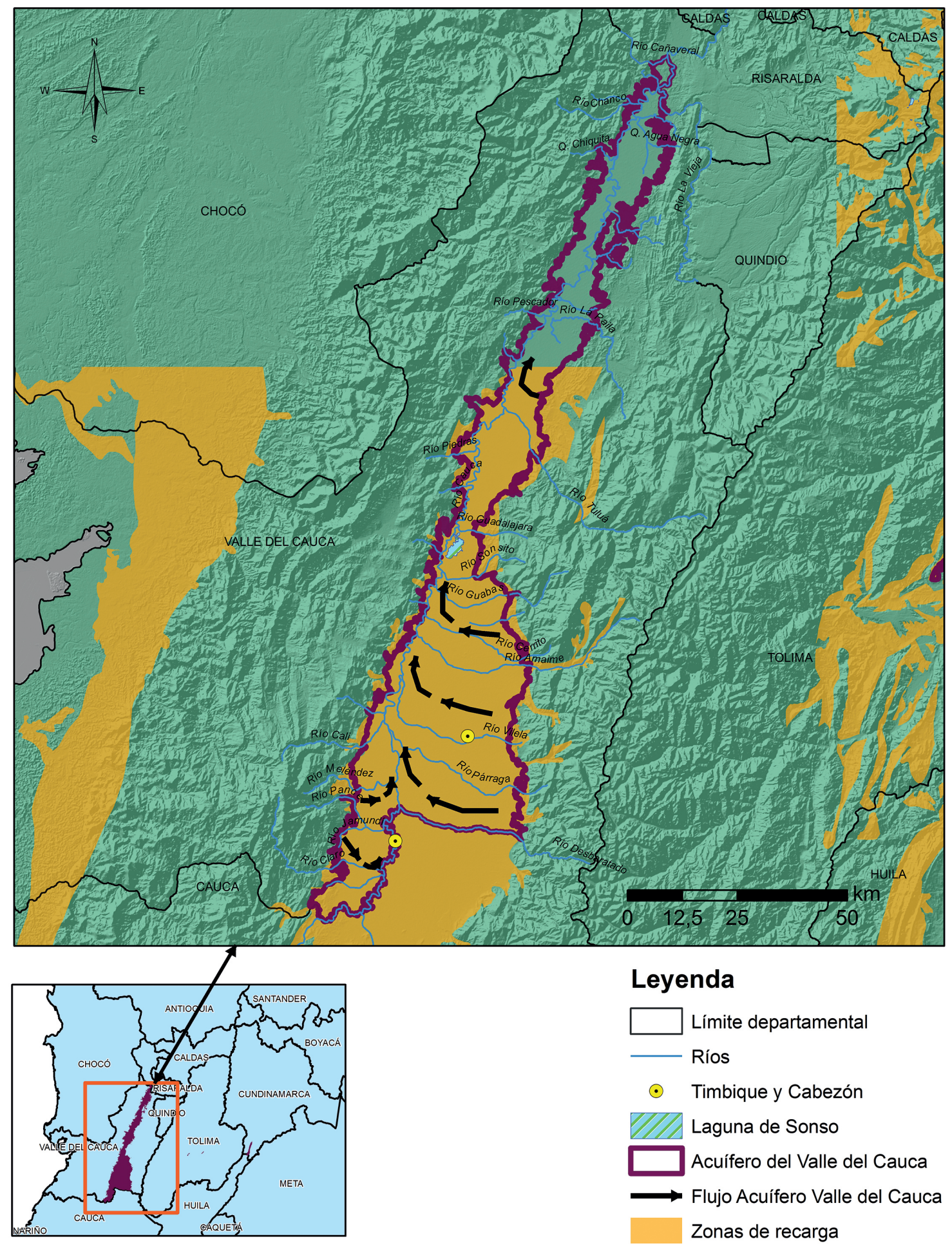

Figura 11. Humedales y acuífero del Valle del Cauca, líneas de flujo y zonas de recarga. 
Hoy los servicios ecosistémicos del humedal Timbique se encuentran en un estado bajo debido a su deterioro. La comunidad está realizando acciones para cambiar este panorama.

\section{Descarga de aguas subterráneas en humedales}

Los sistemas de flujo de aguas subterráneas conocidos en Colombia revelan la presencia de humedales en las zonas de descarga de los acuíferos.

Se destaca dentro de este tipo de conexión la presencia de humedales en diferentes ambientes, siendo los más representativos los humedales costeros de Buenavista y La Caimanera, los humedales del rio León en la llanura de inundación del mismo río, los humedales de altiplano de la Sabana de Bogotá, los humedales de Sonso y Cabezón en la llanura de inundación y en meandros abandonados del río Cauca.

En las inmediaciones del río León se encuentra una amplia zona de humedales asociados a su llanura de inundación, tal y como se observa en la representación de las direcciones de flujo (Figura 9); esta sería una zona de descarga de aguas subterráneas del sistema hidrogeológico del Eje Bananero. Debido al aporte de fósforo y nitrógeno proveniente de la materia orgánica y fertilizantes, este complejo se encuentra en estado eutrófico (U de M y Corpourabá 2014), por lo tanto, el servicio de abastecimiento de agua de buena calidad para consumo se encuentra en un estado bajo aunque el agua tiene otros usos, como el riego. En general los servicios que se encuentran en un mejor estado son los culturales. Respecto a los impactos, los más significativos se encuentran relacionados a la extracción de agua por trasvases, deforestación cambios en el uso del suelo por ganadería y agricultura, que deterioran el ecosistema; la tendencia de estos impactos es a aumentar.

En la figura 11 se pueden identificar las zonas de descarga del acuífero del Valle del Cauca (Ideam 2013) y la relación de ella con los humedales Cabezón y Sonso.
Como puede verse en la figura 12, la ciénaga de Buenavista es un humedal costero localizado en la zona de descarga del sistema hidrogeológico de la cuenca del río Ranchería, específicamente sobre el acuífero libre de Ranchería (Corpoguajira y Universidad de Antioquia 2013).

Este sistema hidrogeológico está compuesto por seis unidades acuíferas: acuífero libre de Ranchería, acuífero multicapa de Monguí, acuífero libre de Oca, acuífero libre de Fonseca, acuífero multicapa El Cerrejón y acuífero Cogollo. La ciénaga Buenavista recibe aportes de la marea, río Ranchería y desde el nivel freático; según se puede concluir a partir de (Invemar et al. 2009), presta servicios ambientales relacionados con regulación hídrica, producción de materia primas biológicas, control de la erosión y paisajísticos y estéticos; aunque hay una marcada tendencia de esos servicios a empeorar, ya que se presentan impactos negativos por intervención antrópica donde se identifica una explotación intensiva del acuífero y un alto grado de deforestación que deteriora el ecosistema.

\section{Servicios ecosistémicos de humedales relacio- nados con agua subterránea en Colombia}

Aplicando el criterio metodológico de priorización adoptado para este trabajo, el cual se soporta en la disponibilidad de información, tanto en relación con la caracterización de sistemas hidrogeológicos como de humedales, que además debían coincidir en su ubicación para poder establecer la relación entre ambos, se identificaron catorce humedales para los cuales se efectuó una primera evaluación de servicios ecosistémicos y factores de impacto sobre los servicios. Se reconocieron humedales de diferente tipo, ambiente, origen y génesis, tanto continentales como costeros, ciénagas, charcos, lagunas y embalses. Para todos ellos los aportes de agua freática representa una característica predominante de su origen, combinado con escorrentía, precipitación y marea. Todos los humedales están siendo intervenidos por actividad humana, lo cual en mayor o menor medida ha modificado su funcionalidad. 


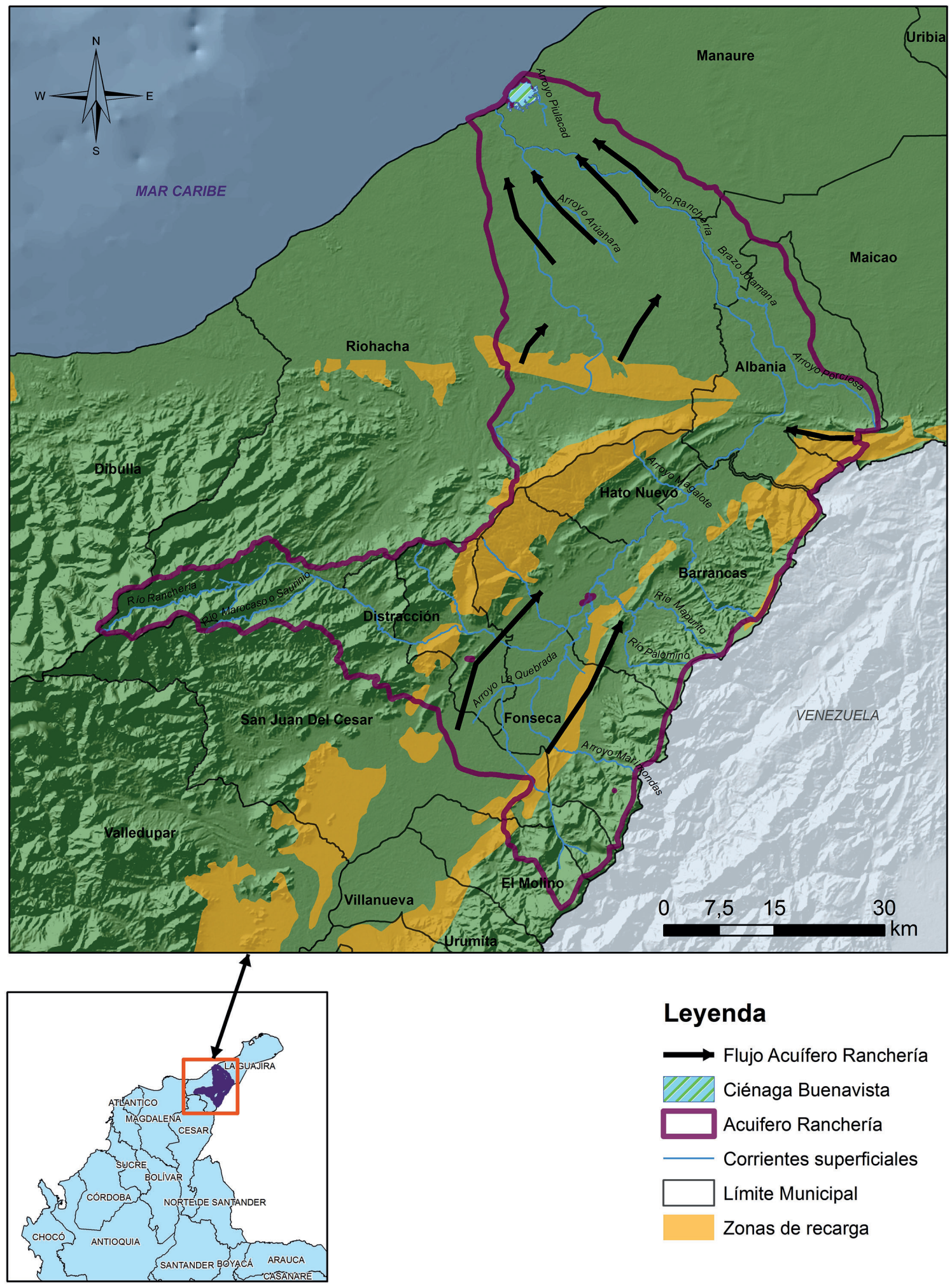

Figura 12. Ciénaga Buenavista, acuífero de la cuenca del río Ranchería, líneas de flujo y zonas de recarga. 
En la figura 13 se resume el estado de los servicios ecosistémicos de los humedales considerados. En relación con los servicios de abastecimiento, el estado es entre alto y medio para el suministro de agua y recursos alimentarios. Como se preveía desde el inicio, los humedales cumplen funciones de regulación hídrica, depuración de agua y control de la erosión. Finalmente se identifica la prestación de servicios turísticos, educativos, paisajísticos y de identidad cultural dentro de la categoría de servicios culturales. Deberá ser objeto de análisis en materia de gestión la condición de tendencia en todos los servicios ya que se reconoce que ella va en el sentido de empeorar.

Los hallazgos en relación con los factores que inducen cambios en los servicios ecosistémicos de los humedales identificados merecen especial atención. Como puede observarse en la Figura 14, la extracción de agua subterránea tiene un impacto alto para seis humedales y un impacto entre medio y bajo para tres de ellos; este factor de explotación intensiva de recursos hidrogeológicos tendría un impacto comparable con aquellos asociados a la extracción de bosque y a las actividades agrícola y ganadera. Los efectos por descenso del nivel freático también empiezan a ser manifiestos en los humedales.

Una rápida mirada a la tendencia de estos factores de cambio (Figura 15), debe generar alerta acerca del marcado sentido de aumento, seguido de la condición estable. Concordante con esta apreciación se dan las condiciones de tendencia de los impactos relacionados con la extracción de agua subterránea y el descenso del nivel freático.

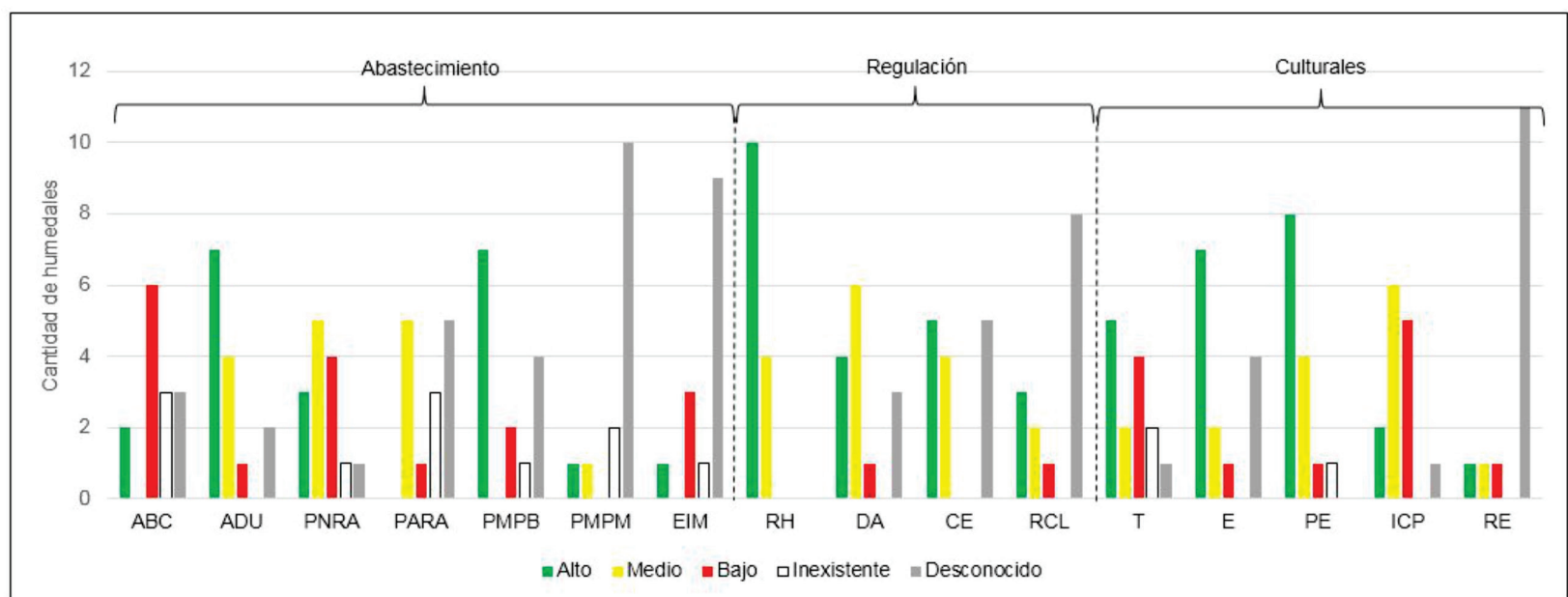

\begin{tabular}{|l|l|l|}
\hline \multicolumn{1}{|c|}{ Abastecimiento } & \multicolumn{1}{c|}{ Regulación } \\
\hline ABC: Abastecimiento de agua de buena calidad & RH: Regulación hídrica & \multicolumn{1}{c|}{ Culturales } \\
\hline ADU: abastecimiento de agua para distintos usos & DA: Depuración de las aguas & T: turísticos \\
\hline PNRA: producción natural de recursos alimentarios. & CE: Control de la erosión & E: Educativos \\
\hline PARA: producción artificial de recursos alimentarios & RCL: Regulación climática local & ICP: Identidad cultural y sentido de pertenencia \\
\hline PMPB: producción de materias primas biológicas & & RE: Religiosos y espirituales \\
\hline PMPM: producción de materias primas minerales & & \\
\hline EIM: especies naturales de interés medicinal. & & \\
\hline
\end{tabular}

Figura 13. Estado de los servicios ecosistémicos de los 14 humedales identificados. 


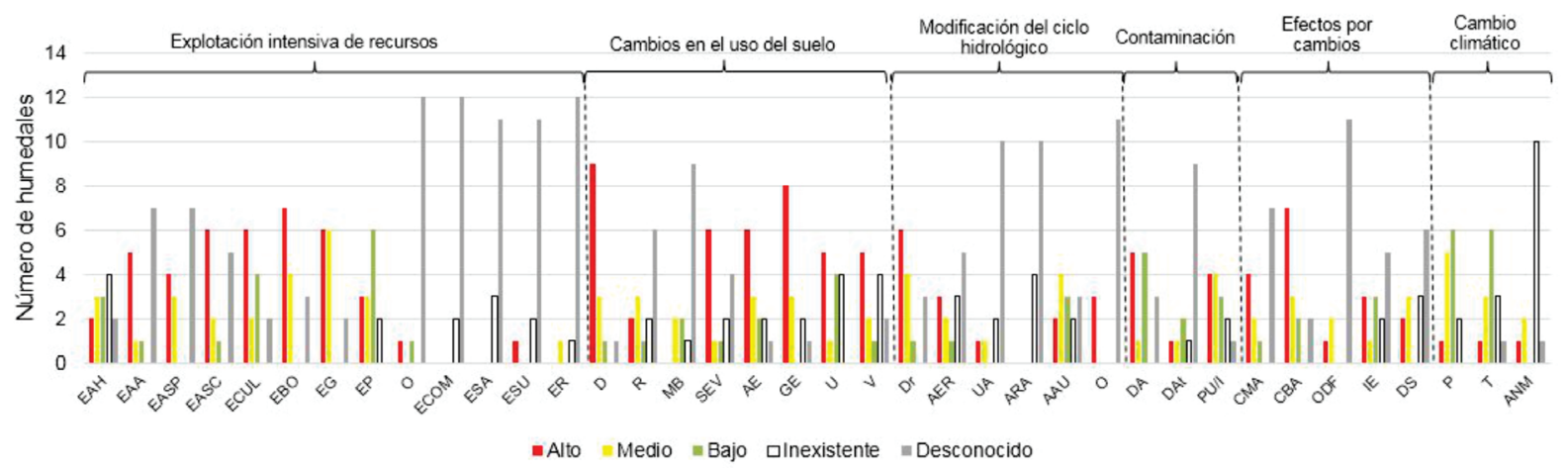

\begin{tabular}{|l|l|l|l|}
\hline \multicolumn{2}{|c|}{ Explotación intensiva de los recursos } & \multicolumn{1}{c|}{ Cambios de uso del suelo } \\
\hline \multicolumn{1}{|c|}{ Extracción de agua } & \multicolumn{1}{|c|}{ Explotación biológica } & \multicolumn{1}{c|}{ Explotación mineral } & D: Deforestación \\
\hline EAH: Del humedal & ECUL: cultivos & ECOM: combustibles & R: Reforestación \\
\hline EAA: De afluentes & EBO: Bosque & ESA: Sales & MB: Manejo del bosque \\
\hline EASP: Agua subterránea próxima & EG: Ganaderia & ESU: Suelos & SEV: Sustitución de especies vegetales \\
\hline EASC: Agua subterránea de la cuenca & EP: Pesca & ER: Rocas & AE: Agricultura extensiva \\
\hline & O: Otros & & GE: Ganaderia extensiva \\
\hline & & & U: Urbanización \\
\hline & & & V: Vias de comunicación \\
\hline \multicolumn{1}{|c|}{ Modificación del ciclo hidrológico } & \multicolumn{1}{|c|}{ Contaminación } & Efectos asociados a cambios & \multicolumn{1}{c|}{ Cambio climático y global } \\
\hline DR: Drenaje & DA: Difusión agricola & CMA: Calidad mineral del agua & P: Precipitación \\
\hline AER: Aportes de excedentes de riego & DAT: Difusión atmosférica & CBA: Calidad biológica del agua & T: Temperatura \\
\hline UA: Uso de almacenamiento & PUn: Puntual urbana / Industrial & ODF: Oxidación por descenso freático & ANM: Aumento del nivel del mar \\
\hline ARA: acciones de recarga artificial & & IE: Incremento de la erosión & \\
\hline AAU: aportes de aguas urbanas & & DS: Destrucción del suelo & \\
\hline O: Otros & & & \\
\hline
\end{tabular}

Figura 14. Factores de cambio en los servicios ecosistémicos de los humedales considerados.

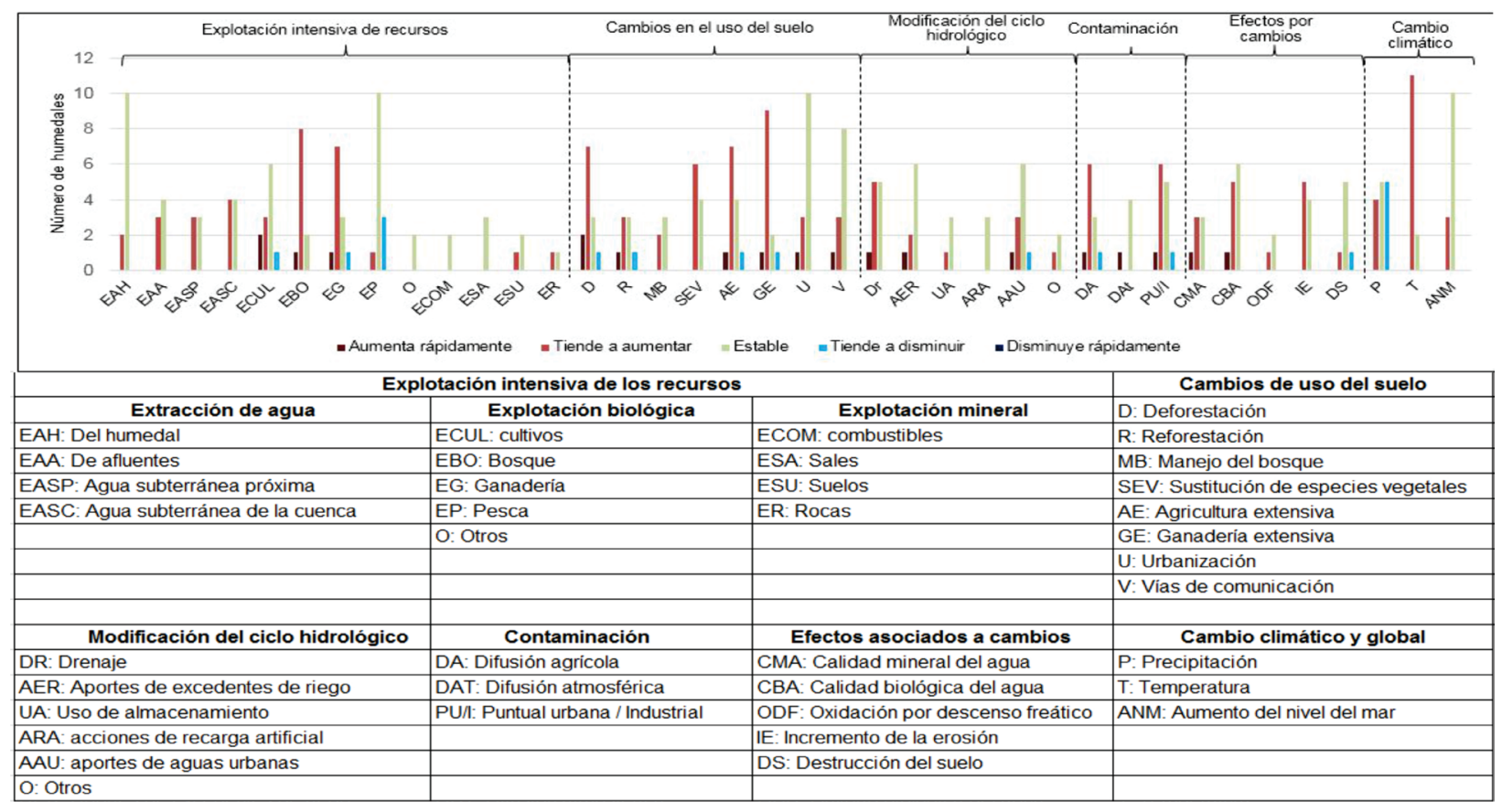

Figura 15. Tendencia de los factores de cambio de los servicios ecosistémicos de los humedales considerados. 
Mirando en conjunto el estado y los impactos sobre los servicios en los catorce humedales hasta ahora considerados, se destacan algunas situaciones especiales. En relación con el estado (Figura 12) de los servicios ecosistémicos, los servicios ecosistémicos de la laguna El Otún se encuentran entre las categorías Medio y Alto, mientras que para en la laguna Sochagota cuatro de los siete servicios de abastecimiento están en estado Bajo; también en el humedal Cabezón tres de los cinco servicios culturales tienen categoría Baja. En lo que concierne a los factores impulsores de cambio (Figura 13), los humedales Laguna de Sonso y conjunto de humedales del río León, relacionados ambos con sistemas hidrogeológicos relevantes en términos de la economía de los departamentos de El Valle del Cauca y Antioquia, registran impactos en categoría Alta, por explotación intensiva de recursos, mientras que sobre el humedal Barbacoas solo se reportan impactos de carácter Medio o Bajo.

\section{Conclusiones}

La relación entre aguas subterráneas y humedales determina en gran medida la sostenibilidad de las funciones y servicios ecosistémicos de estos. A partir de la información disponible en Colombia se ejecuta una primera caracterización en este sentido.

Tras una serie de ejercicios de superposición cartográfica, involucrando información adecuada para sistemas hidrogeológicos, áreas de recarga, zonas y sistemas de humedales, mediante procesos de recarga, flujo o descarga en relación con aguas subterráneas fue posible identificar 14 humedales vinculados con las aguas subterráneas en Colombia.

Para cada uno de los 14 humedales identificados por su vínculo con las aguas subterráneas se realizó una caracterización de los servicios ecosistémicos de abastecimiento, regulación y culturales, aplicando la metodología propuesta en el proyecto Groundwater and wetlands in Iberoamerica. También se identificaron en cada caso los factores de cambio que pueden generar impacto sobre los servicios.
Respecto a los servicios ecosistémicos que prestan los humedales se observa:

1. Los servicios de abastecimiento de agua de buena calidad, producción natural de recursos alimentarios, turísticos, identidad cultural y el sentido de pertenencia predominan en un estado "Bajo".

2. El servicio de abastecimiento de agua para distintos usos tiene una tendencia estable y los de producción de materias primas biológicas, producción natural de recursos alimentarios y servicio paisajístico y estético, tienden a empeorar.

3. Los servicios de regulación tienden, en su mayoría, a empeorar.

4. Con relación a los servicios culturales, los servicios turísticos y educativos tienden a mejorar y los de identidad cultural y sentido de pertenencia tienden a mantenerse estables.

Con relación a los impactos y sus efectos:

1. Los impactos más altos en los servicios ecosistémicos se deben a las actividades cambio del uso del suelo: de deforestación, ganadería extensiva, extracción de agua subterránea de la cuenca, explotación del bosque y efectos asociados a la calidad biológica del agua.

2. Se encontró que las actividades de explotación intensiva pesquera y la difusión de áreas agrícolas predominan como actividades de bajo impacto, así como el cambio de la temperatura y precipitación con relación al cambio climático.

Los resultados que se presentan corresponden a una evaluación parcial, lograda a partir del estado disponible del conocimiento de acuíferos y humedales en Colombia. En la medida en que se tenga mayor y mejor información se podrán realizar análisis más profundos de la relación aguas subterráneashumedales. 
El poder contar con una delimitación del sistema hidrogeológico y una red de monitoreo piezométrica que permita deducir la red de flujo es indispensable para observar la potencial relación. Además, si se cuentan con estudios hidroquímicos e isotópicos de ambos compartimientos, y en general un modelo, ciertamente la identificación de la relación puede ser más precisa. Los Llanos Orientales y La Amazonia deberían ser zonas a priorizar en este sentido.

\section{Agradecimientos}

Este estudio se realizó gracias al convenio $13-014$ (FA. 005 de 2013) que existe entre el IAvH y el Fondo de Adaptación. Agradecemos a los directivos y profesionales que han suministrado información para la realización de este trabajo: Ideam, CRQ, Corantioquia, CDMB, Corpourabá y Cortolima.

\section{Referencias}

ADESSA, Empresa de Acueducto y Alcantarillado de Bogotá. 2006. Plan de Manejo Ambiental Humedal Jaboque. Bogotá D.C. 601 pp.

Arana, V., T. Betancur, M. Hernández y M.V. Vélez. 2015. Identificación y evaluación de servicios ecosistémicos estratégicos de los humedales del río León como base para su valoración económica. Pp: 5. En: Cuarto congreso internacional de servicios ecosistémicos en los neotrópicos: de la investigación a la acción. Mar del Plata, Argentina.

Betancur, T. 2014. Atlas Hidrogeológico del bajo Cauca antioqueño. Medellín. 103 pp.

Betancur, T., E. Bocanegra, M. Manzano, E. Custodio y G. Cardozo. 2015. Evaluación de bienes y servicios ecosistémicos en humedales vinculados a aguas subterráneas en Iberoamérica. Pp. 4. En: Cuarto congreso internacional de servicios ecosistémicos en los neotrópicos: de la investigación a la acción. Mar del Plata, Argentina.

Betancur, T., E. Bocanegra, E. Custodio, M. Manzano y G. Cardoso da Silva. 2016. Estado y factores de cambio de los servicios ecosistémicos de aprovisionamiento en humedales relacionados con aguas subterráneas en Iberoamérica y España. Biota Colombiana 16 (Suplemento 1- Humedales): 106-119. DOI: 10.21068/ c2016s01a06.

Bocanegra, E., M. Manzano, E. Custodio, T. Betancur y G. Cardoso da Silva. 2014. Análisis de las acciones de gestión en humedales que brindan servicios altos al bienestar humano en Iberoamérica. Pp. 83. En: Actas V Congreso Colombiano de Hidrogeología. Medellín, Colombia.

Boyd, J. y S. Banzhaf. 2007. What are ecosystem services? The need for standardized environmental accounting units. Ecological Economics 63: 616 - 626.

Carpenter, S. R., J. Agard, H. A. Mooney, D. Capistrano, R. S. De Fries, S. Díaz, T. Dietz, A. K. Duraiappah, A.Oteng-Yeboah, H. M. Pereira, C. Perrings, W.V. Reid, J. Sarukhan, R. J. Scholes y A. Whyte. 2009. Science for managing ecosystem services: Beyond the Millenium ecosystem assessment. Procceedings of the National Academy of Sciences of the United States of America 106: 1305-1312.

Corporación Autónoma Regional del Centro de Antioquia (CORANTIOQUIA), Neotrópicos. 2000. Ciénagas de la Región Panzenú: Informe final, Resumen. Medellín. 12 pp.

Corporación Autónoma Regional del Centro de Antioquia (CORANTIOQUIA), Neotrópicos. 2001. Diseño e Implementación Inicial de los Componentes Institucional y Operativo de Visión Panzenú. 156 pp.

Corporación Autónoma Regional del Centro de Antioquia (CORANTIOQUIA). 2005. Plan de manejo ambiental del complejo cenagoso Barbacoas. Medellín. 163 pp.

Corporación Autónoma Regional para la Defensa de la Meseta de Bucaramanga (CDMV). 2010. Declaración de un área protegida. Distrito regional de manejo integrado, complejo ciénagas Papayal. Rionegro, Bucaramanga. 31 pp.

Corporación Autónoma Regional de Risaralda (CARDER), Parques Nacionales Naturales de Colombia. 2013. Plan de Manejo Ambiental de la Zona Ramsar "Complejo de Humedales del Otún" Parque Nacional Natural los Nevados. Pereira. 55 pp.

Corporación Autónoma Regional del Valle del Cauca (CVC), Fundación para la protección, conservación y vigilancia de los recursos naturales del sur del Valle (FUNECOROBLES). 2009. Plan de Manejo Ambiental Madrevieja Cabezón. Valle del Cauca. 143 pp.

Corporación Montañas, Corporación Autónoma Regional del Centro de Antioquia (CORANTIOQUIA). 2006a. Informe final del plan de manejo ambiental Ciénaga de Corrales. Medellín. 184 pp.

Corporación Montañas, Corporación Autónoma Regional del Centro de Antioquia (CORANTIOQUIA). 2006b. Plan de manejo ambiental del complejo cenagoso de Chiqueros y su área de influencia en el municipio de Puerto Berrío. Antioquia, 212 pp.

Costanza, R., R. D’Arge, R. de Groot, S. Farber, M. Grasso, B. Hannon, K. Limburg, S. Naeem, R. V. O'Neill, J. 
Paruelo, R. G. Raskin, P. Sutton y M. van den Belt. 1997. The value of the world's ecosystem services and natural capital. Nature 387: 253-260.

Custodio, E. y R. M. Llamas. 1976. Hidrología subterránea. Barcelona. $2350 \mathrm{pp}$.

Custodio, E. 2010. Las aguas subterráneas como elemento básico de la existencia de numerosos humedales. Ingeniería del Agua 17: 119 - 135.

Daily, G. C. 1997. Nature's services. Societal Dependence on Natural Ecosystems. Washington, D. C. Covelo, California. 392 pp.

Dennehy, K. F., T. E. Reilly y W. L. Cunningham. 2015. Groundwater availability in the United States: the value of quantitative regional assessments. Hydrogeology Journal 23:1629-1632.

Duque, C., M. Benjumea, M. Fernándezy T. Betancur. 2014. Plan de Manejo Ambiental de Acuífero según la norma colombiana. Caso de estudio: cuenca del río Ranchería. Pp. 9. En: V Congreso Colombiano de Hidrogeología. Agua subterránea: recurso, bien, derecho, patrimonio. Medellín, Colombia.

Evaluación de los ecosistemas del milenio (EEM). 2005. Los ecosistemas y el bienestar humano: humedales $\mathrm{y}$ agua. Informe síntesis. World Resources Institute, Washington D.C. 68 pp.

Fisher B., K. R. Turner, P. Morling. 2009. Defining and classifying ecosystem services for decision making. Ecological Economics 68: 643 - 653.

Flórez C., L. M. Estupiñán-Suárez, S. Rojas, C. Aponte, M. Quiñones, O. Acevedo, S. Vilardy y U. Jaramillo. 2015. Identificación espacial de los sistemas de humedales continentales Colombia. Biota Colombiana 17: 44 - 62.

Fundación Alimento (FUNDALIMENTO). 2005. Plan de Manejo Participativo Humedal Timbique. Valle del Cauca. 157 pp.

Glynn, P. D. y L. N. Plummer. 2005. Geochemistry and the understanding of ground-water systems. Hydrogeology Journal 13: 263 - 287.

Gómez, A. M. 2010. Propuesta metodológica para la generación de un modelo hidrológico conceptual: Aplicación a la cuenca del río Man. Bajo Cauca antioqueño. Trabajo de maestría. Universidad de Antioquia, Facultad de Ingeniería. Medellín. 152 pp.

Instituto de Hidrología, Meteorología y Estudios Ambientales (Ideam). 2013. Aguas Subterráneas en Colombia: Una Visión General. Bogotá D.C. 284 pp.

Instituto de Hidrología, Meteorología y Estudios Ambientales (Ideam). 2015. Estudio Nacional del Agua. Bogotá D. C. 496 pp.

Instituto de Investigaciones Marinas y Costeras (Invemar), Corporación Autónoma Regional de la Guajira
(Corpoguajira), Ministerio de Ambiente, Vivienda y Desarrollo Territorial. 2009. Ordenamiento ambiental de los manglares de la alta, media y baja Guajira. Caribe colombiano. $340 \mathrm{pp}$.

Joyce S., L. Hartley, D. Applegate, J. Hoek y P. Jackson. 2014. Multi-scale groundwater flow modeling during temperate climate conditions for the safety assessment of the proposed high-level nuclear waste repository site at Forsmark, Sweden. Hydrogeology Journal 22: 1233 $-1249$.

Lasso, C. A., F. de P. Gutiérrez y D. Morales-B. (Editores). 2014. X. Humedales interiores de Colombia: identificación, caracterización y establecimiento de límites según criterios biológicos y ecológicos. Serie Editorial Recursos Hidrobiológicos y Pesqueros Continentales de Colombia. Instituto de Investigación de Recursos Biológicos Alexander von Humboldt. Bogotá, D.C. Colombia. 255 pp.

Leguizamón J. (Editor). 2010. Diagnóstico biofísico del complejo de humedales de la cuenca alta del río Quindío. Informe Técnico. Corporación Autónoma Regional del Quindío (CRQ). Quindío, Colombia. $72 \mathrm{pp}$.

Llamas R. 1993. Explotación de Aguas subterráneas y explotación de ecosistemas. Pp. 193-208. En: Pernía J. M., F. Cuesta, B. Ballesteros, J. Barba-Romero y E. García. Aguas subterráneas, importancias y perspectivas. España.

Margat, J. y J. van der Gun. 2013. Groundwater around the world: A geographic synopsis. Unesco-PHI/IGRAC/ CRC. 376 pp.

McEwan, K., I. Jolly, y K. Holland. 2006. Groundwatersurface water interactions in arid/semi-arid wetlands and the consequences of salinity for wetland ecology. CSIRO Land and Water. Australia. $36 \mathrm{pp}$.

Montoya, D. 2010. Modelo conceptual y numérico del sistema hidrológico Ciénaga Colombia. Bajo Cauca Antioqueño. Tesis de Maestría, Universidad de Antioquia. Medellín. 227 pp.

Montoya, D. M. y J. I. Gaviria. 2011. Las aguas subterráneas un recurso vital para la sostenibilidad. Corantioquia. Medellín. 340 pp.

National Groundwater Association (Compilador). 2015. Facts about global groundwater usage. United States of America. 2 pp.

Organización de las Naciones Unidas para la Educación la Ciencia y la Cultura (Unesco). 1971. Convención relativa a los humedales de importancia internacional. Ramsar. Irán. 6 pp.

Osorio-Peláez, C., C. A. Lasso y F. Trujillo (Editores). 2015. XIII. Aplicación de criterios bioecológicos para 
la identificación, caracterización y establecimiento de límites funcionales en humedales de las sabanas inundables de la Orinoquia. Serie Editorial Recursos Hidrobiológicos y Pesqueros Continentales de Colombia. Instituto de Investigación de Recursos Biológicos Alexander von Humboldt (IAvH). Bogotá, D. C. Colombia, 426 pp.

Pontificia Universidad Javeriana, Empresa de Acueducto y Alcantarillado de Bogotá. 2009. Plan de Manejo Ambiental Humedal de Techo. Bogotá D.C. 202 pp.

Santa, D. P., T. Betancur y D. C. Martínez. 2008. Relaciones hidrogeoquímicas e isotópicas entre los elementos superficial y subterráneo del sistema hidrológico ciénaga Colombia Pp. 53. En: Libro de Resúmenes Primer Congreso Nacional de Ciénagas y Lagunas de Colombia. Homenaje al profesor Thomas van der Hammen. Universidad de Antioquia, Universidad Nacional de Colombia, Medellín - Bogotá D. C.

Santa, D. 2010. Identificación de interacciones hidrológicas entre el humedal ciénaga Colombia y el acuífero libre del Bajo Cauca Antioqueño mediante la utilización de técnicas hidroquímicas. Trabajo de Maestría, Universidad de Antioquia. Medellín. 118 pp.

Schot, P. y T. Winter. 2006. Groundwater-surface water interactions in wetlands for integrated water resources management. Journal of Hydrology 320 (3-4): 261-263.

Servicio Geológico Colombiano (SGC). 2013. Plan estratégico de conocimiento geológico del territorio Colombiano 2013-2023. Bogotá D. C. 123 pp.

Shiklomanov, I. A. 1997. Comprehensive assessment of the freshwater resources of the world. World Meteorological Organization. $88 \mathrm{pp}$.

Universidad de Medellín, Corporación para el desarrollo sostenible del Urabá (Corpurabá). 2014. Sistemas hídricos Sector Río León, Suriquí, Ciénaga de Tumaradó. En el marco del desarrollo de actividades científicas y tecnológicas. Línea de investigación de Geomática Aplicada a los Recursos Naturales, grupo Gema. Medellín. 57 pp.

Universidad Industrial de Santander. 2010. Identificación de las características hidrológicas y sanitarias del lago Sochagota y de fuentes de agua termomineral en el municipios de Paipa. Boyacá. 56 pp.

Universidad Nacional de Colombia sede Bogotá, Instituto para el Desarrollo de Antioquia (Idea). 2006. Formulación del Plan de Manejo Ambiental del Parque Ecológico Distrital Humedal Tibanica. Bogotá D. C. $206 \mathrm{pp}$.

Vilardy, S., U. Jaramillo, C. Flórez., J. Cortés-Duque, L. Estupiñán, J. Rodríguez, C. Aponte. 2014. Principios y criterios para la delimitación de humedales continentales: una herramienta para fortalecer la resiliencia y la adaptación al cambio climático en Colombia. Instituto de Investigación de Recursos Biológicos Alexander von Humboldt. Bogotá D.C. 100 pp.

Villegas, P., V. Paredes, T. Betancur y R. Luís. 2013 Assessing the hydrochemistry of the Urabá Aquifer, Colombia by principal component analysis. Journal of Geochemical Exploration 13: 120-129.

Wada, Y., L. P. H. van Beek, y F. P. Bierkens. 2012. Nonsustainable groundwater sustaining irrigation: A global assessment. Water Resources Research 48: 1-18.

Winter, T.C., J. W. Harvey, O. L. Franke, y W. M. Alley. 1998. Groundwater and surface water a single resource. U.S. Geological Survey Circular 1139. 87 pp. 
Teresita Betancur-Vargas

Universidad de Antioquia, Medellín, Colombia

teresita.betancur@udea.edu.co

Daniel Alejandro García-Giraldo

Universidad de Antioquia,

Medellín, Colombia

dalejandro.garcia@udea.edu.co

Angélica Julieth Vélez-Duque

Universidad de Antioquia,

Medellín, Colombia

ayuvelezz@gmail.com

\section{Angélica María Gómez}

Universidad de Antioquia,

Medellín, Colombia

angelica.gomez@gmail.com

Carlos Flórez-Ayala

Instituto Alexander von Humboldt

Bogotá D.C., Colombia

cflorez@humboldt.org.co

Jorge E. Patiño

Instituto Alexander von Humboldt

Bogotá D.C., Colombia

jpatinoq@eafit.edu.co

Juan Álvaro Ortíz-Tamayo

Universidad de Antioquia,

Medellín, Colombia

juanalvaroortiz@hotmail.com
Aguas subterráneas, humedales y servicios ecosistémicos en Colombia

Citación del artículo: Betancur-Vargas, T., D. A. GarcíaGiraldo, A. J. Vélez-Duque, A. M. Gómez, C. Flórez-Ayala, J. Patiño y J. A. Ortíz-Tamayo. 2017. Aguas subterráneas, humedales y servicios ecosistémicos en Colombia. Biota Colombiana 18 (1): 1-28. DOI: 10.21068/c2017.v18n01a1
Recibido: 10 de diciembre de 2015

Aprobado: 16 de febrero de 2017 


\section{Guía para autores}

(humboldt.org.co/es/bibliotecaypublicaciones/biota)

\section{Preparación del manuscrito}

El envío de un manuscrito implica la declaración explícita por parte del autor(es) de que este no ha sido previamente publicado, ni aceptado para su publicación en otra revista u otro órgano de difusión científica. Todas las contribuciones son de la entera responsabilidad de sus autores y no del Instituto de Investigación de Recursos Biológicos Alexander von Humboldt, ni de la revista o sus editores.

Los trabajos pueden estar escritos en español, inglés o portugués, y se recomienda que no excedan las 40 páginas (párrafo espaciado a 1,5 líneas) incluyendo tablas, figuras y anexos. En casos especiales el editor podrá considerar la publicación de trabajos más extensos, monografías o actas de congresos, talleres o simposios. De particular interés para la revista son las descripciones de especies nuevas para la ciencia, nuevos registros geográficos y listados de la biodiversidad regional.

Para la elaboración de los textos del manuscrito se puede usar cualquier procesador de palabras (preferiblemente Word); los listados (a manera de tabla) deben ser elaborados en una hoja de cálculo (preferiblemente Excel). Para someter un manuscrito es necesario además anexar una carta de intención en la que se indique claramente:

1. Nombre completo del (los) autor (es), y direcciones para envío de correspondencia (es indispensable suministrar una dirección de correo electrónico para comunicación directa).

\section{Título completo del manuscrito.}

3. Nombres, tamaños y tipos de archivos suministrados.

4. Lista mínimo de tres revisores sugeridos que puedan evaluar el manuscrito, con sus respectivas direcciones electrónicas.

\section{Evaluación del manuscrito}

Los manuscritos sometidos serán revisados por pares científicos calificados, cuya respuesta final de evaluación puede ser: a) aceptado (en cuyo caso se asume que no existe ningún cambio, omisión o adición al artículo, y que se recomienda su publicación en la forma actualmente presentada); b) aceptación condicional (se acepta y recomienda el artículo para su publicación solo si se realizan los cambios indicados por el evaluador); y c) rechazo (cuando el evaluador considera que los contenidos o forma de presentación del artículo no se ajustan a los requerimientos y estándares de calidad de Biota Colombiana).

\section{Texto}

- Para la presentación del manuscrito configure las páginas de la siguiente manera: hoja tamaño carta, márgenes de $2,5 \mathrm{~cm}$ en todos los lados, interlineado 1,5 y alineación hacia la izquierda (incluyendo título y bibliografía).

- Todas las páginas de texto (a excepción de la primera correspondiente al título), deben numerarse en la parte inferior derecha de la hoja.
- Use letra Times New Roman o Arial, tamaño 12 puntos en todos los textos. Máximo 40 páginas, incluyendo tablas, figuras y anexos. Para tablas cambie el tamaño de la fuente a 10 puntos. Evite el uso de negritas o subrayados.

- Los manuscritos debe llevar el siguiente orden: título, resumen y palabras clave, abstract y key words, introducción, material y métodos, resultados, discusión, conclusiones (optativo), agradecimientos (optativo) y bibliografía. Seguidamente, presente una página con la lista de tablas, figuras y anexos. Finalmente, incluya las tablas, figuras y anexos en archivos separadas, debidamente identificadas.

- Escriba los nombres científicos de géneros, especies y subespecies en cursiva (itálica). Proceda de la misma forma con los términos en latín (p. e. sensu, et al.). No subraye ninguna otra palabra o título. No utilice notas al pie de página.

- En cuanto a las abreviaturas y sistema métrico decimal, utilice las normas del Sistema Internacional de Unidades (SI) recordando que siempre se debe dejar un espacio libre entre el valor numérico y la unidad de medida (p. e. $16 \mathrm{~km}, 23^{\circ} \mathrm{C}$ ). Para medidas relativas como m/seg., use m.seg ${ }^{-1}$.

- Escriba los números del uno al diez siempre con letras, excepto cuando preceden a una unidad de medida (p. e. $9 \mathrm{~cm}$ ) o si se utilizan como marcadores (p. e. parcela 2, muestra 7).

- No utilice punto para separar los millares, millones, etc. Utilice la coma para separar en la cifra la parte entera de la decimal (p. e. 3,1416). Enumere las horas del día de 0:00 a 24:00.

- Exprese los años con todas las cifras sin demarcadores de miles (p. e. 1996-1998). En español los nombres de los meses y días (enero, julio, sábado, lunes) siempre se escriben con la primera letra minúscula, no así en inglés.

- Los puntos cardinales (norte, sur, este y oeste) siempre deben ser escritos en minúscula, a excepción de sus abreviaturas $\mathrm{N}, \mathrm{S}$, $\mathrm{E}, \mathrm{O}$ (en inglés W), etc. La indicación correcta de coordenadas geográficas es como sigue: $02^{\circ} 37^{\prime} 53^{\prime \prime} \mathrm{N}-56^{\circ} 28^{\prime} 53^{\prime \prime} \mathrm{O}$. La altitud geográfica se citará como se expresa a continuación: 1180 m s.n.m. (en inglés $1180 \mathrm{~m}$ a.s.l).

- Las abreviaturas se explican únicamente la primera vez que son usadas.

- Al citar las referencias en el texto mencione los apellidos de los autores en caso de que sean uno o dos, y el apellido del primero seguido por et al. cuando sean tres o más. Si menciona varias referencias, éstas deben ser ordenadas cronológicamente y separadas por comas (p. e. Rojas 1978, Bailey et al. 1983, Sephton 2001, 2001).

- Resumen: incluya un resumen de máximo 200 palabras, tanto en español o portugués como inglés.

- Palabras Clave: máximo seis palabras clave, preferiblemente complementarias al título del artículo, en español e inglés. 


\section{Agradecimientos}

Opcional. Párrafo sencillo y conciso entre el texto y la bibliografía. Evite títulos como Dr., Lic., TSU, etc.

\section{Fotografías, figuras, tablas y anexos}

Refiera las figuras (gráficas, diagramas, ilustraciones y fotografías) sin abreviación (p. e. Figura 3) al igual que las tablas (p. e. Tabla 1). Gráficos (p. e. CPUE anuales) y figuras (histogramas de tallas), preferiblemente en blanco y negro, con tipo y tamaño de letra uniforme. Deben ser nítidas y de buena calidad, evitando complejidades innecesarias (por ejemplo, tridimensionalidad en gráficos de barras); cuando sea posible use solo colores sólidos en lugar de tramas. Las letras, números o símbolos de las figuras deben ser de un tamaño adecuado de manera que sean claramente legibles una vez reducidas. Para el caso de las fotografías y figuras digitales es necesario que estas sean guardadas como formato tiff con una resolución de 300 dpi. Es oportuno que indique en qué parte del texto desea insertarla.

Lo mismo aplica para las tablas y anexos, los cuales deben ser simples en su estructura (marcos) y estar unificados. Presente las tablas en archivo aparte (Excel), identificadas con su respectivo número. Haga las llamadas a pie de página de tabla con letras ubicadas como superíndice. Evite tablas grandes sobrecargadas de información y líneas divisorias o presentadas en forma compleja. Es oportuno que indique en qué parte del texto desea insertar tablas y anexos.

\section{Bibliografía}

Contiene únicamente la lista de las referencias citadas en el texto. Ordénelas alfabéticamente por autores y cronológicamente para un mismo autor. Si hay varias referencias de un mismo autor(es) en el mismo año, añada las letras a, b, c, etc. No abrevie los nombres de las revistas. Presente las referencias en el formato anexo, incluyendo el uso de espacios, comas, puntos, mayúsculas, etc.

\section{Artículo EN REVISTAS}

Agosti, D., C. R. Brandao y S. Diniz. 1999. The new world species of the subfamily Leptanilloidinae (Hymenoptera: Formicidae). Systematic Entomology 24: 14-20.

\section{LIBROS, TESIS E INFORMES TÉCNICOS}

Libros: Gutiérrez, F. P. 2010. Los recursos hidrobiológicos y pesqueros en Colombia. Instituto de Investigación de Recursos Biológicos Alexander von Humboldt. Bogotá, D. C., 118 pp.

Tesis: Cipamocha, C. A. 2002. Caracterización de especies y evaluación trófica de la subienda de peces en el raudal Chorro de Córdoba, bajo río Caquetá, Amazonas, Colombia. Trabajo de grado. Universidad Nacional de Colombia, Facultad de Ciencias, Departamento de Biología. Bogotá D. C., 160 pp.

Informes técnicos: Andrade, G. I. 2010. Gestión del conocimiento para la gestión de la biodiversidad: bases conceptuales y propuesta programática para la reingeniería del Instituto Humboldt. Informe Técnico. Instituto de Investigación de Recursos Biológicos Alexander von Humboldt. Bogotá D. C., 80 pp.

Capítulo en libro o en informe: Fernández F., E. E. Palacio y W. P. MacKay. 1996. Introducción al estudio de las hormigas (Hymenoptera: Formicidae) de Colombia. Pp:349-412. En: Amat, G. D., G. Andrade y F. Fernández (Eds.). Insectos de Colombia. Estudios Escogidos. Academia Colombiana de Ciencias Exactas, Físicas y Naturales \& Centro Editorial Javeriano, Bogotá.

Resumen en congreso, simposio, talleres: Señaris, J. C. 2001. Distribución geográfica y utilización del hábitat de las ranas de cristal (Anura; Centrolenidae) en Venezuela. En: Programa y Libro de Resúmenes del IV Congreso Venezolano de Ecología. Mérida, Venezuela, p. 124.

PÁginas Web

No serán incluidas en la bibliografía, sino que se señalarán claramente en el texto al momento de mencionarlas.

\title{
Guidelines for authors
}

\author{
(humboldt.org.co/es/bibliotecaypublicaciones/biota)
}

\section{Manuscript preparation}

Submitting a manuscript implies the explicit statement by the author(s) that the paper has not been published before nor accepted for publication in another journal or other means of scientific diffusion. Contributions are entire responsibility of the author and not the Alexander von Humboldt Institute for Research on Biological Resources, or the journal and their editors.

Papers can be written in Spanish, English or Portuguese and it is recommended not exceeding 40 pages (with paragraphs spaced at 1,5) including tables, figures and Annex. For special cases, the editor could consider publishing more extensive papers, monographs or symposium conclusions. New species descriptions for science, new geographic records and regional biodiversity lists are of particular interest for this journal.
Any word-processor program may be used for the text (Word is recommended). taxonomic list or any other type of table, should be prepared in spreadsheet aplication (Excel is recommended). To submit a manuscript must be accompanied by a cover letter which clearly indicate $\mathrm{s}$ :

1. Full names, mailing addresses and e-mail addresses of all authors. (Please note that email addresses are essential to direct communication).

2. The complete title of the article.

3. Names, sizes, and types of files provide.

4. A list of the names and addresses of at least three (3) reviewers who are qualified to evaluate the manuscript. 


\section{Evaluation}

Submitted manuscript will have a peer review evaluation. Resulting in any of the following: a) accepted (in this case we assume that no change, omission or addition to the article is required and it will be published as presented.); b) conditional acceptance (the article is accepted and recommended to be published but it needs to be corrected as indicated by the reviewer); and c) rejected (when the reviewer considers that the contents and/or form of the paper are not in accordance with requirements of publication standards of Biota Colombiana).

\section{Text}

- The manuscript specifications should be the following: standard letter size paper, with $2.5 \mathrm{~cm}$ margins on all sides, 1.5-spaced and left-aligned (including title and bibliography).

- All text pages (with the exception of the title page) should be numbered. Pages should be numbered in the lower right corner.

- Use Times New Roman or Arial font, size 12, for all texts. Use size 10 text in tables. Avoid the use of bold or underlining. 40 pages maximum, including tables, figures and annex. For tables use size 10 Times New Roman or Arial Font (the one used earlier).

- The manuscripts must be completed with the following order: title, abstract and key words, then in Spanish Título, Resumen y Palabras claves. Introduction, Materials and Methods, Results, Discussion, conclusions (optional), acknowledgements (optional) and bibliography. Following include a page with the Table, Figure and Annex list. Finally tables, figures and annex should be presented and clearly identified in separate tables.

- Scientific names of genera, species and subspecies should be written in italic. The same goes for Latin technical terms (i.e sensu, et al.). Avoid the use of underlining any word or title. Do not use footnotes.

- As for abbreviations and the metric system, use the standards of the International System of Units (SI) remembering that there should always be a space between the numeric value and the measure unit (e.g., $16 \mathrm{~km}, 23{ }^{\circ} \mathrm{C}$ ). For relative measures such as $\mathrm{m} / \mathrm{sec}$, use $\mathrm{m} \cdot \mathrm{sec}^{-1}$.

- Write out numbers between one to ten in letters except when it precedes a measure unit (e.g., $9 \mathrm{~cm}$ ) or if it is used as a marker (e.g., lot 9, sample 7).

- Do not use a point to seperate thousands, millions, etc. Use a comma to separate the whole part of the decimal (e.g., 3,1416). Numerate the hours of the from 0:00 to 24:00. Express years with all numbers and without marking thousands (e.g., 19961998). In Spanish, the names of the months and days (enero, julio, sábado, lunes) are always written with the first letter as a lower case, but it is not this way in English.

- The cardinal points (north, south, east, and west) should always be written in lower case, with the excpetino of abbreviations $\mathrm{N}, \mathrm{S}, \mathrm{E}, \mathrm{O}$ (in English NW), etc. The correct indication of geographic coordinates is as follows: $02^{\circ} 37^{\prime} 53^{\prime \prime} \mathrm{N}-56^{\circ} 28^{\prime} 53^{\prime \prime} \mathrm{O}$. The geographic altitude should be cited as follows: $1180 \mathrm{~m}$ a.s.l.

- Abbreviations are explained only the first time they are used.
- When quoting references in the text mentioned author's last names when they are one or two, and et al. after the last name of the first author when there are three or more. If you mention many references, they should be in chronological order and separated by commas (e.g., Rojas 1978, Bailey et al. 1983, Sephton 2001, 2001).

- ABSTRACT: include an abstract of 200 words maximum, in Spanish, Portuguese or English.

- KeY WORDS: six key words maximum, complementary to the title.

\section{Pictures, Figures, Tables and Annex}

- Figures (graphics, diagrams, illustrations and photographs) without abbreviation (e.g. Figure 3) the same as tables (e.g., Table 1). Graphics and figures should be in black and white, with uniform font type and size. They should be sharp and of good quality, avoiding unnecessary complexities (e.g., three dimensions graphics). When possible use solid color instead of other schemes. The words, numbers or symbols of figures should be of an adequate size so they are readable once reduced. Digital figures must be sent at 300 dpi and in .tiff format. Please indicate in which part of the text you would like to include it.

- The same applies to tables and annexes, which should be simple in structure (frames) and be unified. Present tables in a separate file (Excel), identified with their respective number. Make calls to table footnotes with superscript letters above. Avoid large tables of information overload and fault lines or presented in a complex way. It is appropriate to indicate where in the text to insert tables and annexes.

\section{Bibliography}

References in bibliography contains only the list of references cited in the text. Sort them alphabetically by authors and chronologically by the same author. If there are several references by the same author(s) in the same year, add letters a, b, c, etc. Do not abbreviate journal names. Present references in the attached format, including the use of spaces, commas, periodss, capital letters, etc.

\section{JOURNAL ARTICLE}

Agosti, D., C. R. Brandao y S. Diniz. 1999. The new world species of the subfamily Leptanilloidinae (Hymenoptera: Formicidae). Systematic Entomology 24: 14-20.

\section{BOOK, THESIS, TECHNICAL REVIEWS}

Book: Gutiérrez, F. P. 2010. Los recursos hidrobiológicos y pesqueros en Colombia. Instituto de Investigación de Recursos Biológicos Alexander von Humboldt. Bogotá, D. C. 118 pp.

Thesis: Cipamocha, C. A. 2002. Caracterización de especies y evaluación trófica de la subienda de peces en el raudal Chorro de Córdoba, bajo río Caquetá, Amazonas, Colombia. Trabajo de grado. Universidad Nacional de Colombia, Facultad de Ciencias, Departamento de Biología. Bogotá D. C. 160 pp.

Technical reviews: Andrade, G. I. 2010. Gestión del conocimiento para la gestión de la biodiversidad: bases conceptuales y propuesta programática para la reingeniería del Instituto Humboldt. Informe 
Técnico. Instituto de Investigación de Recursos Biológicos Alexander von Humboldt. Bogotá D. C. 80 pp.

Book chapter or in review: Fernández F., E. E. Palacio y W. P. MacKay. 1996. Introducción al estudio de las hormigas (Hymenoptera: Formicidae) de Colombia. Pp: 349-412. En: Amat, G. D., G. Andrade y F. Fernández (Eds.). Insectos de Colombia. Estudios Escogidos. Academia Colombiana de Ciencias Exactas, Físicas y Naturales \& Centro Editorial Javeriano, Bogotá.
Symposium abstract: Señaris, J. C. 2001. Distribución geográfica y utilización del hábitat de las ranas de cristal (Anura; Centrolenidae) en Venezuela. En: Programa y Libro de Resúmenes del IV Congreso Venezolano de Ecología. Mérida, Venezuela, p. 124.

WeB PAGES

Not be included in the literature, but clearly identified in the text at the time of mention.

\section{Guía para autores - Artículos de Datos}

www.humboldt.org.co/es/bibliotecaypublicaciones/biota- biotacol@humboldt.org.co www.sibcolombia.net - sib+iac@humboldt.org.co

El objetivo de esta guía es establecer y explicar los pasos necesarios para la elaboración de un manuscrito con el potencial de convertirse en artículo de datos para ser publicado en la revista Biota Colombiana. En esta guía se incluyen aspectos relacionados con la preparación de datos y el manuscrito.

\section{¿Qué es un artículo de datos?}

Un artículo de datos o Data Paper es un tipo de publicación académica que ha surgido como mecanismo para incentivar la publicación de datos sobre biodiversidad, a la vez que es un medio para generar reconocimiento académico y profesional adecuado a todas las personas que intervienen de una manera u otra en la gestión de información sobre biodiversidad.

Los artículos de datos contienen las secciones básicas de un artículo científico tradicional. Sin embargo, estas se estructuran de acuerdo a un estándar internacional para metadatos (información que le da contexto a los datos) conocido como el GBIF Metadata Profile (GMP) ${ }^{1}$. La estructuración del manuscrito con base en este estándar se da, en primer lugar, para facilitar que la comunidad de autores que publican conjuntos de datos a nivel global, con presencia en redes como la Global Biodiversity Information Facility (GBIF) y otras redes relacionadas, puedan publicar fácilmente artículos de datos obteniendo el reconocimiento adecuado a su labor. En segundo lugar, para estimular que los autores de este tipo de conjuntos de datos que aún no han publicado en estas redes de información global, tengan los estímulos necesarios para hacerlo.

Un artículo de datos debe describir de la mejor manera posible el quién, qué, dónde, cuándo, por qué y cómo de la toma y almacenamiento de los datos, sin llegar a convertirse en el medio para realizar un análisis exhaustivo de los mismos, como sucede en otro tipo de publicaciones académicas. Para profundizar en este modelo de publicación se recomienda consultar a Chavan y Penev $(2011)^{2}$.

\section{¿Qué manuscritos pueden llegar a ser artículos de datos?}

Manuscritos que describan conjuntos de datos primarios y originales que contengan registros biológicos (captura de datos de la presencia de un(os) organismo(s) en un lugar y tiempo determinados); información asociada a ejemplares de colecciones biológicas; listados temáticos o geográficos de especies; datos genómicos y todos aquellos datos que sean susceptibles de ser

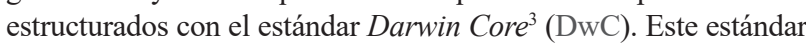
es utilizado dentro de la comunidad de autores que publican conjuntos de datos sobre biodiversidad para estructurar los datos y de esta manera poder consolidarlos e integrarlos desde diferentes fuentes a nivel global. No se recomienda someter manuscritos que describan conjuntos de datos secundarios, como por ejemplo compilaciones de registros biológicos desde fuentes secundarias (p.e. literatura o compilaciones de registros ya publicados en redes como GBIF o IABIN).

\section{Preparación de los datos}

Como se mencionó anteriormente los datos sometidos dentro de este proceso deben ser estructurados en el estándar DwC. Para facilitar su estructuración, el Sistema de Información sobre Biodiversidad de Colombia (SiB Colombia), ha creado dos plantillas en Excel, una para registros biológicos y otra para listas de especies. Lea y siga detenidamente las instrucciones de las plantillas para la estructuración de los datos a publicar. Para cualquier duda sobre el proceso de estructuración de estos datos por favor contactar al equipo coordinador del SiB Colombia (ECSiB) en sib+iac@humboldt.org.co.

\footnotetext{
${ }^{1}$ Wieczorek, J. 2011. Perfil de Metadatos de GBIF: una guía de referencia rápida. En: Wieczorek, J. The GBIF Integrated Publishing Toolkit User Manual, version 2.0. Traducido y adaptado del inglés por D. Escobar. Sistema de Información sobre Biodiversidad de Colombia, Bogotá D.C., Colombia, 23p. Disponible en http://www.sibcolombia.net/repositorio-de-documentos.

${ }^{2}$ Chavan, V. y L. Penev. 2011. The data paper: The mechanism to incentivize data publishing in biodiversity science. BMC Bioinformatics 12 (Suppl 15): S2.

${ }^{3}$ TDWG. 2011. Darwin Core: una guía de referencia rápida. (Versión original producida por TDWG, traducida al idioma español por Escobar, D.; versión 2.0). Bogotá: SiB Colombia, 33 pp. Disponible en http://www.sibcolombia.net/repositorio-de-documentos
} 


\section{Preparación del manuscrito}

Para facilitar la creación y estructuración del manuscrito en el estándar GMP, se cuenta con la ayuda de un editor electrónico (http://ipt.sibcolombia.net/biota) que guiará al autor en dicho proceso y que finalmente generará una primera versión del manuscrito. Se recomienda el uso del manual GMP, como una guía de la información a incluir en cada sección del manuscrito, junto con el anexo 1 .

Pasos a seguir para la elaboración del manuscrito:

1 Solicite al correo sib+iac@humboldt.org.co el acceso al editor electrónico. El EC-SiB le asignará un usuario y contraseña.

2. Ingrese con su usuario y contraseña al editor electrónico, luego diríjase a la pestaña Gestión de recursos y cree un nuevo recurso asignando un nombre corto a su manuscrito usando el formato "AcrónimoDeLaInstitución_año_tipoDeConjuntoDeDatos", p.e. ABC_2010_avestinije y dar clic en el botón crear.

3. En la vista general del editor seleccione "editar" en la pestaña Metadatos (por favor, no manipule ningún otro elemento), allí encontrará diferentes secciones (panel derecho) que lo guiarán en la creación de su manuscrito. Guarde los cambios al finalizar cada sección, de lo contrario perderá la información. Recuerde usar el manual GMP. A continuación se presentan algunas recomendaciones para la construcción del manuscrito. Las secciones se indican en MAYUSCULAS y los elementos de dichas secciones en negrilla.

- En PARTES ASOCIADAS incluya únicamente aquellas personas que no haya incluido en INFORMACIÓN BÁSICA.

- Los DATOS DEL PROYECTO y DATOS DE LA COLECCIÓN son opcionales según el tipo de datos. En caso de usar dichas secciones amplíe o complemente información ya suministrada, p. ej. no repita información de la descripción (COBERTURA GEOGRÁFICA) en la descripción del área de estudio (DATOS DEL PROYECTO).

- De igual manera, en los MÉTODOS DE MUESTREO, debe ampliar o complementar información, no repetirla. La información del área de estudio debe dar un contexto específico a la metodología de muestreo.

- Es indispensable documentar el control de calidad en MÉTODOS DE MUESTREO. Acá se debe describir que herramientas o protocolos se utilizaron para garantizar la calidad y coherencia de los datos estructurados con el estándar DwC.

- Para crear la referencia del recurso, en la sección REFERENCIAS, utilice uno de los dos formatos propuestos (Anexo 2). No llene el identificador de la referencia, este será suministrado posteriormente por el EC-SiB.

- Para incluir la bibliografía del manuscrito en referencias, ingrese cada una de las citas de manera individual, añadiendo una nueva referencia cada vez haciendo clic en la esquina inferior izquierda.

4. Rectifique que el formato de la información suministrada cumpla con los lineamientos de la revista (p. ej. abreviaturas, unidades, formato de números etc.) en la Guía general para autores de Biota Colombiana.

5. Una vez incluida y verificada toda la información en el editor electrónico notifique al EC-SiB al correo electrónico sib+iac@ humboldt.org.co, indicando que ha finalizado la edición del manuscrito. Adicionalmente adjunte la plantilla de Excel con los datos estructurados (elimine todas las columnas que no utilizó). El EC-SiB realizará correcciones y recomendaciones finales acerca de la estructuración de los datos y dará las instrucciones finales para que usted proceda a someter el artículo.

\section{Someter el manuscrito}

Una vez haya terminado la edición de su manuscrito y recibido las instrucciones por parte del EC-SIB, envíe una carta al correo electrónico biotacol@humboldt.org.co para someter su artículo, siguiendo las instrucciones en la Guía general para autores de Biota Colombiana.

Recuerde adjuntar:

- Plantilla de Excel con la última versión de los datos revisada por el EC-SiB.

- Documento de Word con las figuras y tablas seguidas de una lista las mismas.

Cuando finalice el proceso, sus datos se harán públicos y de libre acceso en los portales de datos del SiB Colombia y GBIF. Esto permitirá que sus datos estén disponibles para una audiencia nacional e internacional, manteniendo siempre el crédito para los autores e instituciones asociadas. 
Anexo 1. Estructura base de un artículo de datos y su correspondencia con el editor electrónico basado en el GMP.

\begin{tabular}{|c|c|}
\hline SECCIÓN/SUBSECCIÓN & CORRESPONDENCIA CON LOS ELEMENTOS DEL EDITOR ELECTRÓNICO \\
\hline TÍTUlo & Derivado del elemento título. \\
\hline AutORES & Derivado de los elementos creador del recurso, proveedor de los metadatos y partes asociadas. \\
\hline AFILIACIONES & $\begin{array}{l}\text { Derivado de los elementos creador del recurso, proveedor de los metadatos y partes asociadas. } \\
\text { De estos elementos, la combinación de organización, dirección, código postal, ciudad, país y } \\
\text { correo electrónico, constituyen la afiliación. }\end{array}$ \\
\hline AUTOR DE CONTACTO & Derivado de los elementos creador del recurso y proveedor de los metadatos. \\
\hline Citación & Para uso de los editores. \\
\hline CitACIÓN DELE RECURSO & Derivada del elemento referencia del recurso. \\
\hline RESUMEN & Derivado del elemento resumen. Máximo 200 palabras. \\
\hline Palabras clave & Derivadas del elemento palabras clave. Máximo seis palabras. \\
\hline ABSTRACT & Derivado del elemento abstract. Máximo 200 palabras. \\
\hline KEY WORDS & Derivadas del elemento key words. Máximo seis palabras. \\
\hline INTRODUCCIÓN & $\begin{array}{l}\text { Derivado del elemento propósito (de las secciones Introducción y Antecedentes). Se sugiere un } \\
\text { breve texto para introducir las siguientes secciones. Por ejemplo, historia o contexto de la colección } \\
\text { biológica o proyecto en relación con los datos descritos, siempre y cuando no se repita información } \\
\text { en las subsecuentes secciones. }\end{array}$ \\
\hline Datos del proyecto & $\begin{array}{l}\text { Derivada de los elementos de la sección Datos del proyecto: título, nombre, apellido, rol, fuentes } \\
\text { de financiación, descripción del área de estudio y descripción del proyecto. }\end{array}$ \\
\hline Cobertura taxonómica & $\begin{array}{l}\text { Derivada de los elementos de la sección Cobertura taxonómica: descripción, nombre científico, } \\
\text { nombre común y categoría. }\end{array}$ \\
\hline Cobertura geográfica & $\begin{array}{l}\text { Derivada de los elementos de la sección Cobertura geográfica: descripción, latitud mínima, } \\
\text { latitud máxima, longitud mínima, longitud máxima. }\end{array}$ \\
\hline Cobertura temporal & Derivada de los elementos de la sección Cobertura temporal: tipo de cobertura temporal. \\
\hline Datos de la colección & $\begin{array}{l}\text { Derivada de los elementos de la sección Datos de la colección: nombre de la colección, } \\
\text { identificador de la colección, identificador de la colección parental, método de preservación } \\
\text { de los especímenes y unidades curatoriales. }\end{array}$ \\
\hline MATERIAL Y MÉTODOS & $\begin{array}{l}\text { Derivado de los elementos de la sección Métodos de muestreo: área de estudio, descripción del } \\
\text { muestreo, control de calidad, descripción de la metodología paso a paso. }\end{array}$ \\
\hline \multicolumn{2}{|l|}{ RESUltados } \\
\hline Descripción del conjunto de datos & $\begin{array}{l}\text { Derivado de los elementos de las secciones Discusión y Agradecimientos, contiene información } \\
\text { del formato de los datos y metadatos: nivel de jerarquía, fecha de publicación y derechos de } \\
\text { propiedad intelectual. }\end{array}$ \\
\hline Discusión & $\begin{array}{l}\text { Se deriva del elemento discusión. Un texto breve (máximo } 500 \text { palabras), que puede hacer } \\
\text { referencia a la importancia, relevancia, utilidad o uso que se le ha dado o dará a los datos en } \\
\text { publicaciones existentes o en posteriores proyectos. }\end{array}$ \\
\hline AGRADECIMIENTOS & Se deriva del elemento agradecimientos. \\
\hline BiBLIOGRAFÍA & Derivado del elemento bibliografía. \\
\hline
\end{tabular}


Anexo 2. Formatos para llenar el elemento referencia del recurso.

La referencia del recurso es aquella que acompañará los datos descritos por el artículo, públicos a través de las redes SiB Colombia y GBIF. Tenga en cuenta que esta referencia puede diferir de la del artículo. Para mayor información sobre este elemento contacte al EC-SiB. Aquí se sugieren dos formatos, sin embargo puede consultar otros formatos establecidos por $\mathrm{GBIF}^{4}$.

\section{TIPO DE RECURSO}

El conjunto de datos que el manuscrito describe es resultado de un proyecto de carácter institucional o colectivo con múltiples participantes.

\section{PLANTILLA}

$<$ Institución publicadora/ Grupo de investigación $>$ $<$ (Año) $>$, $<$ Título del recurso/Artículo $>$. $<$ Número total de registros $>$, <aportados por: $><$ parte asociada 1 (rol), parte asociada $2(\mathrm{rol})(\ldots)>$. $<$ En línea, $><$ url del recurso $>$. $<$ Publicado el DD/MM/ AAAA $>$.

\section{EJEMPLO}

Centro Nacional de Biodiversidad (2013). Vertebrados de la cuenca de la Orinoquia. 1500 registros, aportados por Pérez, S. (Investigador principal, proveedor de contenidos, proveedor de metadatos), M. Sánchez (Procesador), D. Valencia (Custodio, proveedor de metadatos), R. Rodríguez (Procesador), S. Sarmiento (Publicador), V. B. Martínez (Publicador, editor). En línea, http://ipt.sibcolombia.net/biota/resource.do?r=verte_orin, publicado el 01/09/2013.

Valencia, D., R. Rodríguez y V. B. Martínez (2013). Vertebrados de la cuenca del Orinoco. 1500 registros, en línea, http://ipt.sibcolombia.net/biota/ resource.do?r=verte orin. Publicado el 01/09/2001.
El conjunto de datos que el manuscrito describe es resultado de una iniciativa personal o de un grupo de investigación definido.
$<$ Parte asociada 1, parte asociada $2(\ldots)>$ $<$ (Año) $>$, $<$ Título del recurso/Artículo $>$, $<$ Número total de registros $>$, <en línea, $><$ url del recurso $>$. $<$ Publicado el DD/MM/AAAA $>$

\section{Guidelines for authors - Data Papers}

www.humboldt.org.co/es/bibliotecaypublicaciones/biota- biotacol@humboldt.org.co|

www.sibcolombia.net - sib+iac@humboldt.org.co

The purpose of this guide is to establish and explain the necessary steps to prepare a manuscript with the potential to become a publishable data paper in Biota Colombiana. This guide includes aspects related to the preparation of both data and the manuscript.

\section{What is a Data Paper?}

A data paper is a scholarly publication that has emerged as a mechanism to encourage the publication of biodiversity data as well as an approach to generate appropriate academic and professional recognition to all those involved in in the management of biodiversity information.

A data paper contains the basic sections of a traditional scientific paper. However, these are structured according to an international standard for metadata (information that gives context to the data) known as the GBIF Metadata Profile (GMP)5. The structuring of the manuscript based on this standard enables the community of authors publishing datasets globally, with presence in networks such as the Global Biodiversity Information Facility (GBIF) and other related networks, to publish data easily while getting proper recognition for their work and to encourage the authors of this type of data sets that have not yet published in these global information networks to have the necessary incentives to do so.

A data paper should describe in the best possible way the Whom, What, Where, When, Why and How of documenting and recording of data, without becoming the instrument to make a detailed analysis of the data, as happens in other academic publications. To deepen this publishing model, it is recommended to consult Chavan \& Penev (2011) ${ }^{6}$.

\footnotetext{
${ }^{4}$ GBIF (2012). Recommended practices for citation of the data published through the GBIF Network. Version 1.0 (Authored by Vishwas Chavan), Copenhagen: Global Biodiversity Information Facility. Pp.12, ISBN: 87-92020-36-4. Accessible at http://links.gbif.org/gbif_best_practice_data_citation_ en_v1

${ }^{5}$ GBIF (2011). GBIF Metadata Profile, Reference Guide, Feb 2011, (contributed by O Tuama, E., Braak, K., Copenhagen: Global Biodiversity Information Facility,19 pp. Accesible at http://links.gbif.org/gbif_metadata_profile_how-to_en_v1.

${ }^{6}$ Chavan, V. y L. Penev. 2011. The data paper: The mechanism to incentivize data publishing in biodiversity science. BMC Bioinformatics 12 (Suppl 15): S2.
} 
Guía para aut ores - Artículos de Datos / Guidelines for authors - Data Papers

\section{Which manuscripts are suitable for publication as data paper?}

Manuscripts that describe datasets containing original primary biological records (data of occurrences in a particular place and time); information associated with specimens of biological collections, thematic or regional inventories of species, genomic data and all data likely to be structured with the standard Darwin CoreDarwin Core $^{7}$ (DwC). This standard is used in the community of authors publishing biodiversity datasets to structure the data and thus to consolidate and integrate from different sources globally. It is not recommended to submit manuscripts describing secondary datasets, such as biological records compilations from secondary sources (e.g. literature or compilations of records already published in networks such as GBIF or IABIN).

\section{Dataset preparation}

As mentioned above data submitted in this process should be structured based on DwC standard. For ease of structuring, the Biodiversity Information System of Colombia (SiB Colombia), created two templates in Excel; one for occurrences and other for species checklist. Carefully read and follow the template instructions for structuring and publishing data. For any questions about the structure process of data please contact the Coordinator Team of SiB Colombia (EC-SiB) at sib+iac@humboldt.org.co

\section{Manuscript preparation}

To assist the creation and structuring of the manuscript in the GMP standard, an electronic writing tool is available (http://ipt. sibcolombia.net/biota) to guide the author in the process and ultimately generate a first version of the manuscript. The use of GMP manual as an information guide to include in each section of the manuscript, as well as the annex 1 is recommended.

Steps required for the manuscript preparation:

1 Request access to the electronic writing tool at sib+iac@ humboldt.org.co. The EC-SiB will assign a username and password.

2. Login to the electronic writing tool, then go to the tab Manage Resources and create a new resource by assigning a short name for your manuscript and clicking on the Create button. Use the format: "InstitutionAcronym_Year_DatasetFeature", e.g. NMNH 2010 rainforestbirds.

3. In the overview of the writing tool click on edit in Metadata section (please, do not use any other section), once there you will find different sections (right panel) that will guide you creating your manuscript. Save the changes at the end of each section, otherwise you will lose the information. Remember to use the GMP manual. Here are some recommendations for editing the metadata, sections are indicated in CAPS and the elements of these sections in bold.
- In ASSOCIATED PARTIES include only those who are not listed in BASIC INFORMATION.

- PROJECT DATA and COLLECTION DATA are optional depending on the data type. When using these sections extend or complement information already provided, i.e. do not repeat the same information describing the description (GEOGRAPHIC COVERAGE) in the study area description (PROJECT DATA).

- Likewise, in SAMPLING METHODS, you must expand or complete the information, not repeat it. The information in study extent should give a specific context of the sampling methodology.

- It is essential to document the quality control in SAMPLING METHODS. Here you should describe what tools or protocols were used to ensure the quality and consistency of data structured with DwC standard.

- To create the resource citation in the CITATIONS section, follow one of the two formats proposed (Annex 2). Do not fill out the citation identifier, this will be provided later by the EC-SiB.

- To include the manuscript bibliography in citations, enter each of the citations individually, adding a new citation each time by clicking in the bottom left.

4. Check that the format of the information provided meets the guidelines of the journal (e.g. abbreviations, units, number formatting, etc.) in the Biota Colombiana Guidelines for Authors.

5. Once included and verified all information in the writing tool, notify to EC-SiB at sib+iac@humboldt.org.co, indicating that you have finished editing the manuscript. Additionally attach the Excel template with structured data (remove all columns that were not used). The EC-SiB will perform corrections and final recommendations about the structure of the data and give you the final instructions to submit the paper.

\section{Submit the manuscript}

Once you have finished editing your manuscript and getting the instructions from EC-SIB, send a letter submitting your article to email biotacol@humboldt.org.co, following the instructions of Biota Colombiana Guidelines for Authors.

Remember to attach:

- Excel template with the latest version of the data reviewed by the EC-SiB.

- Word document with figures and tables followed by a list of them.

At the end of the process, your information will be public and freely accessible in the data portal of SiB Colombia and GBIF. This will allow your data to be available for national and international audience, while maintaining credit to the authors and partner institutions.

\footnotetext{
${ }^{7}$ Biodiversity Information Standards - TDWG. Accesible at http://rs.tdwg.org/dwc/terms/
} 
Annex 1. Basic structure of a data paper and its mapping to the writing tool elements based on GM.

\begin{tabular}{|c|c|}
\hline $\begin{array}{l}\text { SECTION/SUB-SECTION } \\
\text { HEADING }\end{array}$ & MAPPING WITH WRITING TOOL ELEMENTS \\
\hline TITLE & Derived from the title element. \\
\hline Authors & Derived from the resource creator, metadata provider, and associated parties elements. \\
\hline AfFILIATIONS & $\begin{array}{l}\text { Derived from the resource creator, metadata provider and associated parties elements. From } \\
\text { these elements combinations of organization, address, postal code, city, country and email } \\
\text { constitute the affiliation. }\end{array}$ \\
\hline CORRESPONDING AUTHOR & Derived from the resource contact, metadata provider elements. \\
\hline Citation & For editors use. \\
\hline RESOURCE CITATION & Derived from the resource citation element. \\
\hline RESUMEN & Derived from the resumen element. 200 words max. \\
\hline Palabras Clave & Derived from the palabras clave element. 6 words max. \\
\hline ABSTRACT & Derived from the abstract element. 200 words max. \\
\hline KEY WORDS & Derived from the key words element. 6 words max. \\
\hline INTRODUCTION & $\begin{array}{l}\text { Derived from the purpose (Introduction and Background section). A short text to introduce the } \\
\text { following sections is suggested. For example, history or context of the biological collection or } \\
\text { project related with the data described, only if that information is not present in subsequent sections. }\end{array}$ \\
\hline Project data & $\begin{array}{l}\text { Derived from elements title, personnel first name, personnel last name, role, funding, study } \\
\text { area description, and design description. }\end{array}$ \\
\hline Taxonomic Coverage & $\begin{array}{l}\text { Derived from the taxonomic coverage elements: description, scientific name, common name } \\
\text { and rank. }\end{array}$ \\
\hline Geographic Coverage & Derived from the geographic coverage elements: description, west, east, south, north. \\
\hline Temporal Coverage & Derived from the temporal coverage elements: temporal coverage type. \\
\hline Collection data & $\begin{array}{l}\text { Derived from the collection data elements: collection name, collection identifier, parent } \\
\text { collection identifier, specimen preservation method and curatorial units. }\end{array}$ \\
\hline MATERIALS AND METHODS & $\begin{array}{l}\text { Derived from the sampling methods elements: study extent, sampling description, quality } \\
\text { control and step description. }\end{array}$ \\
\hline \multicolumn{2}{|l|}{ RESUltados } \\
\hline Descripción del conjunto de datos & $\begin{array}{l}\text { Derived from the discussion and acknowledgments, contains information about the format of the } \\
\text { data and metadata: hierarchy level, date published and ip rights. }\end{array}$ \\
\hline DisCUSSION & $\begin{array}{l}\text { Derived from the discussion element. A short text ( } \max 500 \text { words), which can refer to the } \\
\text { importance, relevance, usefulness or use that has been given or will give the data in the published } \\
\text { literature or in subsequent projects. }\end{array}$ \\
\hline ACKNOWLEDGMENTS & Derived from the acknowledgments element. \\
\hline BIBLIOGRAPHY & Derived from the citations element. \\
\hline
\end{tabular}


Annex 2. Citation style quick guide for "resource reference" section.

The Resource Reference is the one that refer to the dataset described by the paper, publicly available through SiB Colombia and GBIF networks. Note that this reference may differ from the one of the paper. For more information about this element contact EC-SiB.

Here two formats are suggested; however you can consult other formats established by GBIF .

\section{TYPE OF RESOURCE}

The paper is the result of a collective or institutional project with multiple participants.

The paper is the result of a personal initiative or a defined research group.

\section{TEMPLATE}

$<$ Institution/Research Group $>$. < Year $>,<$ Title of the Resource/Paper $>$. $<$ Number of total records $>$, <provided by :> <associated party 1 (role), associated party 2 (role), (...) > $<$ Online, $>$ $<$ resource URL $>$, $<$ published on $>$. $<$ Published on DD/MM/AAAA $>$.

$<$ associated party 1 , associated party $2,(\ldots)>$. $<$ Year $>$, $<$ Title of the Resource/Paper $>$, $<$ Number of total records $>,<$ Online, $><$ resource URL $>$. $<$ Published on DD/MM/AAAA $>$.

\section{EXAMPLE}

National Biodiversity (2013). Vertebrates in Orinoco, 1500 records, provided by: Perez, S. (Principal investigator, content provider), M. Sanchez (Processor), D. Valencia (Custodian Steward, metadata provider), R. Rodriguez (Processor), S. Sarmiento (Publisher), VB Martinez (Publisher, Editor). Online, http://ipt.sibcolombia.net/ biota/resource.do? $\mathrm{r}=$ verte orin, published on 01/09/2013.

Valencia, D., R. Rodríguez and V. B. Martínez. (2013). Vertebrate Orinoco Basin, 1500 records, Online, http://ipt.sibcolombia.net/biota/resource. do? $\mathrm{r}=$ verte_orin, published on 01/09/2001

${ }^{8}$ GBIF (2012). Recommended practices for citation of the data published through the GBIF Network. Version 1.0 (Authored by Vishwas Chavan), Copenhagen: Global Biodiversity Information Facility. Pp.12, ISBN: 87-92020-36-4. Accessible at http://links.gbif.org/gbif_best practice_data_citation en $\mathrm{v} 1$ 


\section{TABLA DE CONTENIDO / TABLE OF CONTENTS}

Aguas subterráneas, humedales y servicios ecosistémicos en Colombia. Groundwater, wetlands and ecosystem services in Colombia. Teresita Betancur-Vargas, Daniel A. García-Giraldo, Angélica J. Vélez-Duque, Angélica M. Gómez, Carlos Flórez-Ayala, Jorge Patiño y Juan Á. Ortiz-Tamayo

Efecto del $\mathrm{CaCl}_{2}$ sobre el contenido de proteínas, prolina, acidez titulable, clorofila y contenido relativo de agua de $A$ loe vera expuesta a salinidad por $\mathrm{NaCl}$. $\mathrm{CaCl}_{2}$ effect on protein, proline, titratable acidity, chlorophyll and relative water content from Aloe vera exposed to salinity by NaCl. Selwin Pérez-Nasser .... Efecto del $\mathrm{Ca}^{2+}$ sobre algunas variables de crecimiento de Aloe vera cultivada con $\mathrm{NaCl}$. Effect of $\mathrm{Ca}^{2+}$ on some growth variables from Aloe vera grown on $\mathrm{NaCl}$. Selwin Pérez-Nasser

Charophyta, Chlorophyta y Cryptophyta del embalse Riogrande II (Antioquia), Colombia. Charophyta, Chlorophyta and Cryptophyta in Riogrande II reservoir (Antioquia), Colombia. Mónica T. López Muñoz, Carlos E. De Mattos-Bicudo, Ricardo O. Echenique, John J. Ramírez-Restrepo y Jaime A. Palacio ................ Diferencias del contenido nutricional de hojas jóvenes y maduras de dos especies de puya (Puya santosii Cuatrec., Puya goudotiana Mez; Bromeliaceae), en la región del Guavio, Cundinamarca, Colombia. Differences in the nutritional content of mature and young Puya leaves (Puya santosii Cuatrec., Puya goudotiana Mez; Bromeliaceae) in the Guavio region, Cundinamarca, Colombia. Luis J. Romero-Puentes, Brayan L. Torres-Clavijo y Angela ParradoRosselli

Características físicas y germinativas de semillas de la orquídea Prosthechea sp. de la zona andina, Fusagasugá, Colombia. Physical and germinative characteristics of Prosthechea sp. (Orchidaceae) native to Fusagasugá - Colombia. Laguandio del C. Banda-Sánchez, Yeison H. Pinzón-Ariza y Luis E. Vanegas-Martínez

Especies vegetales colonizadoras de áreas perturbadas por la minería en bosques pluviales del Chocó, Colombia. Colonizer plant species of sites disturbed by mining in the Chocoan rain forests, Colombia. Hamleth Valois-Cuesta y Carolina Martinez-Ruiz

Catálogo de la flora vascular de los Parques Nacionales de Colombia: Santuario de Flora y Fauna de Iguaque y su zona de amortiguamiento. Catalog of the vascular flora of the National Parks of Colombia: Iguaque Fauna and Flora Sanctuary and buffer zone. Humberto Mendoza-Cifuentes .....

Cambios estructurales del mesozooplancton en relación a las condiciones hidrográficas en el golfo de Cariaco, Venezuela. Structural changes of mesozooplankton in relation to hydrographic conditions in the Gulf of Cariaco, Venezuela. Brightdoom Márquez-Rojas, Evelyn Zoppi de Roa, Luis Troccoli y Edy Montiel

Chinches patinadoras marinas (Hemiptera: Heteroptera: Gerromorpha): diversidad de los hábitats oceánicos del Neotrópico. Marine water striders (Hemiptera: Heteroptera: Gerromorpha): diversity of ocean habitats in the Neotropics. Fredy Molano-Rendón e Irina Morales

Descripción de una nueva especie de mariposa del género Wahydra Steinhauser (Lepidoptera: Hesperiidae: Hesperiinae: Anthoptini) para Colombia. Description of a new species of butterfly of the genus Wahydra Steinhauser (Lepidoptera: Hesperiidae: Hesperiinae: Anthoptini) from Colombia. Efrain R. Henao-Bañol, Fabián G. Gaviria y Julián A. Salazar-Escobar

Pseudoescorpiones (Arachnida: Pseudoscorpiones) del nororiente andino de Colombia. Pseudoscorpions (Arachnida: Pseudoscorpiones) in the norteastern Andean region of Colombia. Catalina Romero-Ortiz

Primer registro de cuatro especies de camarones de agua dulce (Palaemonidae) para Colombia. First records of four species of freshwater shrimp (Palaemonidae) from Colombia. Ada Acevedo y Carlos A. Lasso

Lista anotada de los tipos de peces en la colección del Laboratorio de Ictiología, Universidad del Quindío, Armenia, Colombia (IUQ). Annotated list of types of fishes in the collection of the Laboratory of Ichthyology, University of Quindío, Armenia, Colombia (IUQ). César Román-Valencia, Donald C. Taphorn, Carlos. A. García-Alzate, Sebastián Vásquez-P. y Raquel I. Ruiz-C........

Pterygoplichthys undecimalis (Siluriformes: Loricariidae): una especie trasplantada en la cuenca del río Patía, vertiente Pacífico, Colombia. Pterygoplichthys undecimalis (Siluriformes: Loricariidae): a species transplanted to the Basin of the Patía River, Colombia. Alberto Moncayo-Fernández, Ofelia Mejía-Egas y Héctor E. Ramirez-Chaves

Lista anotada de la herpetofauna del departamento del Quindío, Colombia. Checklist of the herpetofauna of the department of Quindío, Colombia. Cristian Román-Palacios, Sara Fernández-Garzón, Alejandro Valencia-Zuleta, Andrés F. Jaramillo-Martínez y Ronald A. Viáfara-Vega

Batracofauna de los bosques de niebla y estribaciones del piedemonte en el municipio de Yopal (Casanare), Orinoquia colombiana. Frogs and toads of cloud forests and foothills in the Yopal municipality (Casanare), Colombia. Andrés R. Acosta-Galvis

Jagüeyes y su papel potencial en la conservación de tortugas continentales en el golfo de Morrosquillo, Sucre, Caribe colombiano. Cattle ponds and their potential role in conservation of freshwater turtles in the Gulf of Morrosquillo, Sucre, Colombia. Jaime De La Ossa-V., Merly Ardila-Marulanda, Alejandro De La Ossa-Lacayo

Aspectos poblacionales de primates diurnos simpátricos que habitan parches de bosque seco tropical en los Montes de María, Sucre, Colombia. Populational aspects of diurnal sympatric primates inhabiting patches of tropical dry forest in the Montes de María, Sucre, Colombia. Jaime De La Ossa-V. $y$ Silvia Galván-Guevara

Diversidad de pequeños mamíferos no voladores (Didelphimorphia, Paucituberculata y Eulipotyphla) en Áreas de Protección Estricta de Venezuela. Diversity of non-volant small mammals (Didelphimorphia, Paucituberculata and Eulipotyphla) in the Strictly Protected Areas in Venezuela. Franger J. García, Mariana I. Delgado-Jaramillo y Marjorie Machado

La integridad biológica como herramienta de valoración cuantitativa del estado de conservación del bosque seco en Colombia. Biological integrity as a tool for quantitative assessment of the conservation status of dry forest in Colombia. Wilmar Bolivar-García, Alan Giraldo y Ángela M. González-Colorado

Nota

Ampliación de la distribución geográfica de Microgenys minuta Eigenmann 1913 (Characiformes, Characidae) en la cuenca del río Magdalena, Colombia. Expansion of distribution of Microgenys minuta Eigenmann 1913 (Characiformes, Characidae) in the Magdalena River basin, Colombia. Lina M. Mesa-S. $y$ Juan G. Albornoz

\section{Artículo de datos}

Colección Ictiológica de la Universidad Industrial de Santander, Colombia. Ichthyology Collection of the Industrial University of Santander, Colombia. Mauricio Torres, Egna Mantilla-Barbosa, Federico Rangel-Serpa.....

Guía para autores. Guidelines for authors 